\title{
Aproximación a la filosofía de Hegel*
}

Luis Armando González

\section{Introducción}

Con Hegel, el idealismo alemán adquiere su máxima expresión y desarrollo y abre un horizonte de reflexión filosófica que, con su perspectiva y problemática, se arraigó profundamente en el pensamiento filosófico posthegeliano. Indudablemente, Hegel expresa la síntesis última y plena realización conceptual de ese movimiento filosófico que tiene sus raíces en Kant y que continúa ulteriormente en Fichte y Schelling. Esto se puede constatar — sin profundizar desde luego en la cuestión- al analizar los temas mejor logrados en la filosofía hegeliana - una concepción clara de la dialéctica de lo real y una concepción totalizadora del proceso histórico- que, de algún modo, ya se venían prefigurando en la problemática pre-hegeliana, especialmente en los autores mencionados. Como escribe E. Terrón, en el "Prólogo" a la Introducción a la Historia de la filosofia de Hegel: "La filosofía de Hegel es la última gran filosofía especulativa. En ella finalizan y se articulan todos los movimientos del pensamiento del pasado. La filosofía de Hegel contiene todos lo momentos del desarrollo del pensamiento... pero superados y unificados"(1).

Con todo, la importancia de Hegel no se agota ni por expresar el punto más alto de la reflexión idealista alemana ni por estar operante en el pensar filosófico moderno, sino por otros motivos, entre los que sobresalen los siguientes: en

* Este texto sirvió de base para el curso "Filosofía idealista alemana y posthegeliana", servido por el autor al Departamento de Filosofía de la UCA, en el semestre 02 de 2001 
primer lugar, con Hegel la sociedad burguesa cobra, en tanto que sociedad burguesa, la más alta comprensión de sí misma; o, mejor aún, en el pensamiento hegeliano se expresa —como quizá en ningún otro pensador anterior o posterior - la visión más elaborada que la modernidad burguesa puede lograr de sí misma. Y, en segundo lugar, el pensamiento teológico hegeliano desarrolla una serie de supuestos que serán claves en la reflexión teológica del siglo XX.

Pasemos, entonces, a la exposición de las tesis básicas de la metafísica hegeliana, haciendo énfasis en sus momentos y aspectos centrales.

\section{La metafisica hegeliana}

En general, pueden distinguirse tres grandes planos de la reflexión metafísica de Hegel. En primer lugar, está el plano en el que se describe la totalidad de lo real tal como aparece; pero como aparece en y por el hombre. Este es el plano fenomenológico de la metafísica hegeliana. "La phänomenología -dice A. Kojevees la 'Ciencia de las apariciones del espíritu', es decir, de la totalidad del ser real que se revela a sí mismo por el discurso del hombre que el Ser implica"(2); y que, en tanto que ser real, envuelve como uno de sus momentos básicos al hombre mismo y su praxis.

Pero, en segundo lugar, a Hegel le parece que no basta con la mera descripción fenomenológica de las "apariciones del espíritu" para dar cuenta científica y concretamente de la esencia de lo real. Según él, el filósofo debe preguntarse por cuál deba ser la Realidad-objetiva que últimamente haga posible la aparición de ella misma en tanto que "fenómeno". Como escribe Kojeve: "el Filósofo todavía se pregunta cuál debe ser la realidad objetiva (...), es decir el mundo real [natural y humano], para poder 'aparecer' de la misma manera como 'parece' efectivamente en tanto que 'fenómeno'”. La respuesta a esta pregunta está dada por la metafísica a la cual Hegel llama "Philosophie der natur y Philosophie der Geistes"(3).

En tercer lugar, según Hegel, el nivel de reflexión filosófica anterior es todavía insuficiente - por no transcender hacia la mismidad del ser- para dar cuenta cabal de la esencia de la realidad. esto no puede menos que forzar al filósofo, cree Hegel, hacia un nivel de reflexión en el que la pregunta sea por la índole del propio ser; esto es, a un nivel de reflexión de carácter ontológico.

Como escribe Kojeve: "[superando el plano de la descripción metafísica] el filósofo se eleva al plano ontológico, para responder al interrogante de saber cuál debe ser el propio ser, tomado en tanto que ser, para que pueda realizarse o existir como ese Mundo natural y humano descrito en la metafísica, de la manera descrito en la fenomenología. Y esa descripción de la estructura del Ser en tanto que tal se efectúa en la ontología que Hegel llama Logik"(4).

Por tanto, en la reflexión metafísica hegeliana se encuentran presentes distintos niveles de reflexión sobre la realidad o sobre el ser, los cuales, fundándo- 
se uno sobre otro, dan cuenta de la estructura fenomenológica, metafísica y ontológica de lo real. Tomando como punto de partida el esbozo que hemos hecho de esta filosofía podemos intentar exponer más detalladamente los aspectos señalados. En lo que sigue expondremos a grosso modo la lógica de Hegel, la cual trata de ese ser que se realiza y existe como mundo natural y humano, y que, asimismo, cobra consciencia de sí mismo como espíritu.

\subsection{La lógica (Ontología)}

Ya dijimos que en su reflexión ontológica Hegel pretende dar cuenta de la índole misma de ese ser que se realiza como mundo natural y humano y que, asimismo, cobra consciencia progresiva de sí en el devenir de la historia. Es decir, lo que le interesa es determinar cuál debe ser - como dice Kojeve- el propio ser: el ser que se despliega como naturaleza y como historia. Hegel desarrolla su estudio de la lógica siguiendo un esquema de tríada básico: a) categorías fundamentales del ser; b) categorías fundamentales de la esencia; $y$ c) categorías fundamentales del concepto. Antes de examinar esos temas, hagamos una reflexión previa sobre la lógica, el método y la dialéctica en Hegel.

Lo primero que hay que decir es que la Logik no es para Hegel lo que corrientemente se entiendo por lógica; esto es, no se trata de un problema de las "reglas" del razonamiento verdadero o algo semejante, sino que, en rigor, la lógica es la ciencia del Ser, ciencia que tiene por finalidad revelar su esencia. "La Logik de Hegel —escribe Kojeve- no es una lógica en el sentido corriente del término, ni una gnoseología, sino una ontología o ciencia del ser, tomado en tanto que ser"(4). Lo cual no quiere decir que la "Logik", como ciencia del ser, no envuelva, de algún modo, un momento discursivo o epistemológico. Por supuesto que sí. Pero este discurso (logos) no tiene en la perspectiva hegeliana por sí mismo importancia; la tiene, sí, en cuanto manifiesta la estructura ontológica del Ser. En este sentido, cuando Hegel escribe en la Enciclopedia de las ciencias filosóficas que "el hecho lógico presenta, considerado en su forma, tres conceptos: a) el abstracto racional; b) el dialéctico o negativo-racional; c) el especulativo o positivo-racional"(5), se refiere a lo lógico no como el pensamiento lógico considerado en sí mismo, sino más bien al "ser (Sein) revelado (correctamente) en y por el pensamiento o el discurso (Logos). Los tres aspectos de la cuestión son ante todo aspectos del propio Ser: son categorías ontológicas y no lógicas o gnoseológicas y tampoco por cierto simples artificios del método de investigación o de exposición" (6). Por tanto, comprender mediante la Lógica hegeliana implica comprender el carácter de sus tres momentos constitutivos: el aspecto abstracto, el aspecto dialéctico y el aspecto especulativo; que son -como dice Hegel- "elementos- constitutivos (Momente) de toda entidad Lógico-Real, es decir, de todo concepto o de todo lo-que-es-verdad (...) en general"(7). 
Por ser lo que son, los momentos de la lógica tienen que ser expresados o expuestos por el logos humano, que precisamente lo único que hace es revelar la estructura ontológica del Ser, de la que es componente esencial. Aquí -antes de proseguir- es preciso detenerse y decir dos palabras sobre la idea que del Método hay en Hegel y sobre el papel que éste le asigna a la dialéctica. Obviamente, son dos cuestiones que, además de estar estrechamente ligadas, son sumamente problemáticas. Pero, por ello, son tema obligado para el propósito de este trabajo. Posteriormente, retomaremos la reflexión sobre los momentos constitutivos del ser.

\subsection{Método y dialéctica}

En primer lugar, el problema del método. De entrada digamos que en Hegel no hay, en sentido estricto, un método de investigación de lo real; es decir, no hay un sistema, ya sea conceptual o instrumental, de referencia preconcebido, mediante el cual se pretenda reflexionar sobre la realidad desde una posición de independencia con respecto a ella. Esto, para Hegel, es un absurdo que lo único que hace es deformar lo real y dificultar el despliegue de su movimiento propio. "El hombre ingenuo, el sabio vulgar, el filósofo no hegeliano se oponen cada uno a su manera a lo real y lo deforman oponiéndole medios de acción o métodos de pensamiento que les son propios"(8). Y ello, como de suyo es claro para Hegel, además de ser un modo superficial de investigación, es una forma inadecuada de investigación. Lo que se tiene que hacer es acercarse sin ningún tipo de presupuesto a lo real, y convertir así al propio discurso en un fiel reflejo de su estructura; es decir, que lo que se tiene que hacer es describir el ser propio de las cosas.

En opinión de Kojeve, el sabio, el que tiene la capacidad suficiente para indagar sobre el ser, no tiene otra alternativa que confiar enteramente en lo real, sin oponer resistencias de ninguna índole a sus manifestaciones. "Su papel -insiste Kojevees el de un espejo perfectamente plano y definitivamente extendido: no refleja lo Real; lo Real se refleja en él; se refleja en su consciencia y se revela en su propia estructura dialéctica por el discurso del sabio que la describe sin deformarlo"(9), cosa que no puede ser de otro modo, dada la unidad existente entre el sabio y lo Real.

Por lo cual se puede decir que en Hegel no hay, en sentido estricto, un método de investigación de la estructura del Ser y la Realidad. Lo que hay en Hegel es una descripción positiva de lo Real. Una descripción empírica que, a diferencia de la ciencia-técnica - sólo que busca conocer y transformar la naturaleza y la sociedad en función de los intereses del hombre-, no tiene mayor finalidad que revelar la realidad sin modificarla o perturbarla, es decir, revelarla con absoluta fidelidad. La experiencia hegeliana, escribe Kojeve, "revela la Realidad concreta, y la revela sin modificarla o 'perturbarla'. Por eso cuando descri- 
be verbalmente esa experiencia, representa una Verdad en el sentido estricto del término. Y por ello no tiene un método específico que le sea propio en tanto que experiencia, pensamiento o descripción verbal, y que no sea al mismo tiempo una estructura 'objetiva' de la misma Realidad concreta que revela describiéndola"(10).

En esta perspectiva no hay una separación tajante, ni tan siquiera insinuada, entre el sujeto que estudia lo real y lo Real mismo: lo que se da es la unidad indisoluble de la realidad, del Ser, con el Sujeto que la describe; la unidad de lo Real y el discurso positivo que la revela. "Lo real concreto - escribe Kojevees a la vez Realidad-revelada-por-un-discurso, y Discurso-que-revela-una-realidad. Y la experiencia hegeliana no se relaciona ni con lo real, ni con el discurso revelador, ella misma es un aspecto de lo Real concreto que describe. No aporta nada de afuera y el pensamiento o el discurso que nacen de ella no son sino una reflexión sobre la realidad: es la realidad misma que reflexiona o se refleja en el discurso o en tanto que pensamiento"(11).

En resumen, en el pensamiento hegeliano no hay un método de investigación en el sentido corriente del término. Con un método de investigación se deformaría lo Real, alterando su estructura o atribuyéndole caracteres que no le son propios. Por ello, y para no deformar la índole propia del verdadero Ser, el sabio en vez de acercarse a lo Real con un método debe hacerlo sólo con sus sentidos, dejándose interpelar por la realidad y revelando, por medio de su discurso, lo que esta Realidad Es. Ello es posible no solamente porque el Sabio es un momento de la totalidad de lo Real, sino porque también el Sabio, por ser tal, se halla reconciliado teóricamente con esa Realidad de la cual pretende dar cuenta. Se trata de una reconciliación en la cual el Discurso revelador de lo Real no es más que la Realidad misma reflejándose en el Discurso.

La Realidad, sin ese Discurso revelador de sí misma -que no es más que su propia toma de consciencia- no alcanza su grado mayor de desarrollo; el Discurso Teórico, sin ese despliegue precedente de lo Real, no puede convertirse en su revelador. Sólo tomados a una, Discurso teórico y Realidad, se puede hablar en sentido estricto de Verdadero Ser o de Verdadera Realidad. En otras palabras, si a lo Real le compete como uno de sus momentos constitutivos revelarse a través de un Discurso, cualquier metodología o sistema de hipótesis que pretendan dar cuenta de la esencia de la realidad lo único que harán es dificultar la manifestación plena de él. Lo Real, pues, se expresará de manera plena solamente cuando el Sabio se convierta en un mediador entre la Realidad en devenir y el pensamiento en el que esta cobra conciencia de sí mismas. Este pensamiento no es otra cosa que lo Real mismo en un nivel superior de desarrollo.

En segundo lugar, el problema de la dialéctica. Este tema es central en la reflexión filosófica hegeliana. Se trata de un tema de significación altamente polémica y polivalente. Ante todo, apuntaremos que para Hegel la realidad es 
dialéctica, pero a quien compete por excelencia este carácter es a la realidad histórica. Y ello, aún con todas las polémicas que ha suscitado y pueda seguir suscitando, es un hecho innegable en el pensamiento hegeliano. Incluso, para hablar con exactitud, se puede decir que la realidad natural no posee estrictamente una dimensión dialéctica tal como la que corresponde al ámbito histórico-social. Porque a la sociedad y la historia les es propio el momento dialéctico en razón justamente del elemento humano que las constituye, lo cual no sucede en la naturaleza, puesto que el factor humano está ausente.

No es el factor humano considerado de cualquier modo al que compete un carácter dialéctico, sino considerado como Trabajo, es decir, como actividad negadora de lo dado. Como escribe Kojeve: "el trabajo es pues una negación real de lo dado. El ser que existe en tanto que un mundo donde se trabaja implica pues un elemento negativo o negador"(12). Y el momento central de la dialéctica hegeliana lo constituye la negatividad que le es esencial al trabajo humano. Dicho más claramente: "esta negación activa o Real de lo dado —como apunta Kojeve, que se efectúa en la Lucha y por el Trabajo, constituye el elemento negativo o negador que determina la estructura dialéctica de lo Real y del Ser. Trátase pues de lo real dialéctico y de una dialéctica Real"(13). Así pues, el elemento negativo por excelencia, el elemento dialéctico por antonomasia, lo constituye el trabajo; en sentido amplio, la praxis humana transformadora de lo Real, que, a la vez que determina la estructura dialéctica de la Realidad histórica se realiza, en tanto que praxis, de modo asimismo dialéctico, conformando ambos aspectos un solo y único proceso de desarrollo.

Por tanto, no se puede hablar en Hegel de una Dialéctica de la Naturaleza sin incurrir en una grave deformación de su pensamiento. La dialéctica es, para él, algo que compete propiamente al trabajo humano y, en consecuencia, a la historia y la sociedad. Mas aún, es algo que compete a la totalidad de la realidad — natural e histórica- solo por haber devenido en humanidad. Esto nos lleva a dos aspectos centrales en el planteamiento filosófico hegeliano: a) nos permite hacer una consideración unitaria y estructural de naturaleza e historia, en la cual es imposible tomar por separado cualquiera de ambos elementos y creerlos la verdadera realidad, así como también nos evita darles igual rango de realidad: la historia es más real que lo natural; y b) nos conduce a valorar adecuadamente la índole del pensamiento a través del cual se expresa la estructura de la realidad.

Para Hegel, la naturaleza y la historia forman una unidad que es la Realidad; de ésta sólo puede hablarse una vez que los dos momentos mencionados se han hecho presentes en su pleno desarrollo. Una vez dados, se fundamentan reciproca y mutuamente, puesto que, en el proceso de su devenir, el uno sin el otro no adquieren ni adquirirían una real concreción. Por otro lado, sobre la índole del pensamiento que expresa la estructura dialéctica de lo real (naturaleza e historia) se tiene que decir que, en tanto que pensamiento, no le corresponde de suyo 
tener un carácter dialéctico. Si lo tiene, es únicamente porque la realidad expresada es en sí misma dialéctica. Como apunta Kojeve: "en Hegel hay una dialéctica real, pero el método filosófico es el de una simple y pura descripción, sólo dialéctica en el sentido en que describe una dialéctica de la realidad"(14): este es el caso de la filosofía hegeliana, cuya finalidad expresa es exponer conceptualmente la dialéctica de lo real, su estructura lógica interna, la cual por ser dialéctica —negativa — obliga a una conceptualización igualmente dialéctica o negativa.

Resumamos la idea de la dialéctica que maneja Hegel. Para este autor, la estructura de la realidad histórica - su estructura intrínseca- es dialéctica en virtud de la praxis humana. Así, hablar de una dialéctica de la naturaleza se vuelve problemático. Para comprender a cabalidad lo anterior, remitámonos a un texto de Hegel sobre el tema: "la naturaleza es como ella es; y sus cambios son, por el contrario, solamente repeticiones, su movimiento solamente un curso circular. Inmediatamente su acción [la del espíritu] es conocerla"(15), conocerla en su mecanicidad y circularidad repetitivas. Lo contrario sucede en la Historia, con el espíritu, como diría Hegel, en donde la negatividad y la innovación son lo más esencial. A continuación del texto citado se puede leer lo siguiente: "Yo soy; pero, inmediatamente [como naturaleza], existo en tanto que organismo viviente solamente; como espíritu, existo sólo en tanto que me conozco... conócete a ti mismo, la inscripción sobre el templo del Dios sapiente de Delfos es el mandamiento absoluto, que se expresa la naturaleza del espíritu.

Pero la conciencia contiene esencialmente esto, que yo soy por mí, que soy objeto para mí. Con este juicio absoluto, con la distinción de mi yo de mí mismo, el espíritu se convierte en existencia actual, se pone como exterioridad, que es precisamente el modo universal diferenciador de la existencia de la Naturaleza"(16). Justamente, este ponerse como exterioridad, este ponerme como objeto para mí mismo, para poder así conocerme totalmente, no puede ser logrado si no es por el trabajo y la negatividad que le es consustancial; por la praxis humano-social que consiste radicalmente en un salir de mí mismo, hacia la exterioridad de las propias producciones, para poder luego - a través de esas exteriorizaciones - cobrar una conciencia más plena de sí mismo, de la propia naturaleza. Por tanto, no es errado decir que para Hegel la Dialéctica más real cobra vigencia en la historia, en y por el trabajo humano, en y por la producción de objetos en los que el espíritu humano se aliena a sí mismo, pero que, sin embargo, constituyen la posibilidad absoluta para que el mismo se recupere plenamente, es decir, para que cobre una consciencia más plena de sí.

En resumen, para Hegel es la negatividad propia del trabajo humano la que introduce el fenómeno dialéctico en la realidad, específicamente en la Realidad Histórica. Por ello, es a ésta y no a la Realidad Natural a la que tal carácter compete. La Realidad Natural, nos dice Hegel, es mecánica y repetitiva, no 
dialéctica e innovadora. Dicho esto, volvamos al problema central de esta parte del trabajo: la Lógica.

Recapitulemos algo de lo dicho anteriormente. Señalamos que la lógica de Hegel pretende dar cuenta de la estructura metafísica de la realidad, mejor dicho, de su estructura Ontológica. La Lógica es la expresión teórica de la estructura de la realidad - no es lo mismo que la lógica como sistema o conjunto de leyes y normas de razonamiento; ni tampoco es el resultado de una investigación a partir de métodos científicos, cuyos presupuestos de indagación sobre lo real son las hipótesis y las teorías-. Así pues, la Lógica, la Ciencia de la Lógica, es la Realidad, el Ser, manifestando su esencia en y a través de la inteligencia del hombre, en y a través del discurso filosófico elaborado por el propio Hegel.

Además, para Hegel, es en la Historia en donde se expresa la máxima Realidad del Ser, del absoluto; es justamente en la Historia en donde éste se expande y se autorreconoce más plenamente; en donde cobra plena autoconsciencia de sí. Ello es posible por la dialecticidad que le compete preferentemente a la historia en virtud del Trabajo del hombre y, correlativamente, por las distintas y diversas producciones en las que el espíritu humano se objetiva y se autorreconoce; entre ellas, le corresponde a la Filosofía (hegeliana) el lugar privilegiado. Este privilegio es doble: el hombre se conoce a sí mismo en ella y, al mismo tiempo, capta en su historicidad la lógica intrínseca de la realidad, capta al absoluto realizándose y conociéndose en y por la historia de la humanidad, en y por la historia de la filosofía. Por ello, la Lógica de Hegel no puede ser un conjunto de normas o reglas de razonamiento: es la expresión pensada de la esencia ontológica de lo real, abstraída del devenir histórico-real del espíritu por el pensar filosófico que no es otra cosa que el absoluto manifestándose y cobrando consciencia plena de sí mismo.

Es indudable que para Hegel lo más real de la realidad, su lógica interna, en donde se manifiesta más plenamente es en el ámbito de la historia de la filosofía; y es justo de ahí desde donde el filósofo y la filosofía — tal como lo entiende Hegel- elabora conceptualmente esta Lógica de la Realidad: en la Lógica de Hegel se expresa la lógica de la realidad, su racionalidad, la cual se hace presente a través del Discurso del Filósofo. Como dice Hegel en La introducción a la historia de la filosofía, "es el tema y el menester de la Filosofía misma exponer el único modo de este surgir, la derivación de las formas, la necesidad pensada, conocida, de las determinaciones; y mientras que la idea pura, de la que se trata aquí, no es aún la forma muy particularizada de la mima como naturaleza y como espíritu, entonces es aquella representación principalmente el tema y el menester de la filosofía lógica" (16).

Pero, por otro lado, las distintas formas y determinaciones del Absoluto no aparecen en la realidad en el estado puro en que son expuestas por el filósofo, sino que, aun guardando un rango entitativo propio, aparecen revestidas de un 
contexto histórico que es justo al que se remite el teórico para poder dar cuenta de la esencia lógica de lo Real. Como señala Hegel, "por el otro modo es que las distintas etapas y momentos del desarrollo en el tiempo se destacan en la manera de suceder y en este lugar especial, en este o aquel pueblo, en estas circunstancias políticas y bajo las complicaciones de las mismas; en resumen: bajo esta forma empírica; éste es el drama que nos muestra la historia de la filosofía" (17). Es a ella a donde debe remitirse el filósofo para determinar la Estructura Lógica de la Realidad, cuyas categorías fundamentales, así como la sucesión entre las mismas, guardan una relación estrecha con la historia del pensamiento filosófico, con la continuidad y ruptura dialéctica que se da entre los distintos sistemas filosóficos.

"De acuerdo con esta idea - dice Hegel—, afirmo ahora que la sucesión de los sistemas de filosofía en la historia de la misma es como la sucesión en la derivación lógica de las determinaciones conceptuales de la idea. Afirmo que, cuando se trata de los conceptos fundamentales de los sistemas aparecidos en la historia de la filosofía, de los que se despoja en cuanto a su forma exterior, a su aplicación a lo particular, etc., entonces se conservan las diversas etapas en la determinación de la idea misma en su concepto lógico. Por el contrario, tomado por sólo el progreso lógico, se tiene en él, de acuerdo con sus momentos principales, el progreso de los fenómenos históricos; pero, indudablemente, hay que reconocer estos conceptos puros en el contenido de su forma histórica" (18). Por tanto, el filósofo, en su búsqueda de la esencia metafísica de la realidad, debe remitirse a la máxima densidad Real, a la Historia de la humanidad, y, dentro de ella, a la historia de la filosofía; es en ésta en donde aquélla se manifiesta más plenamente; se manifiesta cobrando consciencia de sí misma en y a través de la filosofía, en y a través de la Historia de la Filosofía. De aquí que, con toda justicia, se puede decir que la Lógica, la Filosofía, además de representar la conceptualización más acabada de la esencia del Ser, de su estructura íntima, representa, asimismo, el grado más alto de autoconciencia, de autoconocimiento, que el absoluto puede lograr de sí mismo. Son dos asuntos que se codeterminan mutuamente.

Pues bien, hemos dicho que la lógica la extrae Hegel preferentemente de la Historia de la Filosofía; y que ella manifiesta ensimismados caras de un mismo proceso metafísico; por el lado del Absoluto, la lógica representa al conocimiento o, mejor dicho, autoconocimiento más profundo que éste puede lograr de sí mismo; por el lado del hombre, representa el conocimiento más elevado que éste puede lograr de sí y del Absoluto. Momentos que son, por tanto, congéneres y unitarios. Por otra parte, la Lógica, en cuanto autoconsciencia plena del propio Absoluto y en cuanto autoconocimiento de él en y por la Historia de la Filosofía, se identifica con ésta: la Lógica es, en tanto que filosofía, Historia de la Filosofía: es en ésta en donde el hombre se conoce más plenamente a sí mismo y al Absoluto y en donde éste se explaya a plenitud cobrando una consciencia 
plena de sí a través del conocimiento filosófico del hombre. Por ello, no es casual que Hegel escriba refiriéndose a las filósofos: "su hazaña es solamente ésta: que han sacado a la luz del día la racional en sí del pozo del Espíritu"(19); es decir, que han sacado la estructura lógica esencial de la realidad en la Historia del pensar filosófico humano, de la historia de la filosofía. Y esto porque, en último término, "la historia de la filosofía — como dice Hegel— se ocupa de lo que no envejece, de lo actualmente vivo"(20), del Absoluto que dinamiza la historia de la humanidad que se realiza en ella. Por ello es que la Logik no es un conocimiento apriorístico de la realidad con el que luego el filósofo aborda los distintos problemas, sino que es fruto de todo un largo proceso de estudio y reflexión sobre la historia humano-social. Es de ella, especialmente de la historia de la filosofía de donde se extrae esa estructura esencial la Lógica de Hegel. Luego, a la luz de ella, se expone conceptualmente el devenir de lo real bajo una nueva perspectiva: la de su lógica interna. La de su racional dialéctica intrínseca; la racionalidad por la cual "la idea produce la Naturaleza que es lo otro de sí misma. Y solamente a través de su opuesto de la naturaleza, de la exteriorización de su esencia, llega a la consciencia de sí misma: este proceso es la historia completa del mundo"(21).

\subsection{Momentos lógicos del discurso}

Tres son estos momentos: a) el aspecto abstracto o accesible al entendimiento; b) aspecto dialéctico o negativamente racional; y c) el aspecto especulativo o positivamente racional (22).

En primer lugar, el momento abstracto o accesible al entendimiento. Este momento lógico (que expresa, repitámoslo una vez más, un momento esencial de la realidad) es definido así por Hegel en la Enciclopedia de las ciencias filosóficas: "el pensamiento, como intelecto se cierra a la determinación rígida y a la diferencia de esta con otras; tal producto abstracto y limitado vale para el intelecto como existente y subsistente por sí"(23). Eso se puede dividir en dos cosas fundamentales. Primero, que visto el elemento abstracto desde el entendimiento, lo que se tiene es una captación unilateral, estrecha y limitada de las determinaciones de lo real, las cuales no son aprehendidas en cuanto tales determinaciones, sino rígidamente y desconectadas de las demás. Segundo, que tomado el pensamiento como un momento de la realidad, de la totalidad, él mismo atraviesa por esa etapa. El pensamiento mismo, en los estadios iniciales de su desarrollo, es un producto abstracto y unilateral, y es justo de esta experiencia de donde se extrae, en lo fundamental, la estructura de la lógica hegeliana.

Lo dicho anteriormente vale para cualquier fenómeno o hecho de la Realidad. Ya sea que sea vista por separado o que se la considere en su conjunto: los fenómenos particulares, sean plantas, animales, hombres o sociedades. Así como la Totalidad de la Realidad entera (naturaleza-hombre-sociedad), atraviesa en los 
momentos iniciales de su desarrollo y de su devenir por esta fase del En Sí, es decir, por la fase de la unilateralidad y la abstracción: sus elementos son, en su despliegue inicial, un "producto" abstracto. En la Doctrina del Ser, siempre en la Enciclopedia, Hegel puntualiza aún más esta idea del momento abstracto. "El puro ser - escribe - marca el inicio, porque tanto es pensamiento puro como a la vez el elemento inmediato, simple e indeterminado; y el primer comienzo no puede ser nada de mediato ni de más precisamente determinado"(24). Es eso lo que Hegel en tantos de sus escritos llama «Ser en Sí» o, mejor dicho, momento del En sí; que es el que envuelve la totalidad de potencialidades a desarrollar en una realidad determinada; el estado que Hegel caracteriza como abstracto. Un texto de la Introducción a la historia de la filosofía complementa al ya citado de la Enciclopedia.

En ese texto dice Hegel: "pero lo que es en sí, no es aún lo verdadero, sino lo abstracto; es el germen de lo verdadero, la aptitud, el ser en sí de la verdadera"(24); es, asimismo, lo que contiene todas las potencialidades de desarrollo de la cosa, todas las cualidades de lo "múltiple en sí". Son esas internas posibilidades las que han de mostrarse en el devenir tanto de las cosas particulares como de la totalidad del Ser. El Ser en Sí es justamente abstracto y unilateral porque no se ha enriquecido todavía en el proceso de desarrollo; aunque, sin embargo, contenga la totalidad de posibilidades y potencialidades de las cosas. Pero sin ese despliegue -es decir, manteniéndose la cosa como ser en sí- su realidad es una realidad abstracta, simple, indeterminada. Y este momento es propio de toda realidad particular (como "pensamiento puro" y como elemento simple), así como la Totalidad de ella en los estadios iniciales de su desarrollo.

El primer momento de la estructura lógica de la realidad -e igualmente de la Lógica como exposición teórica de la misma - lo constituye el aspecto abstracto. Por otro lado, lo abstracto no se agota solamente en ser un momento inicial de lo lógico-Real ni en ser un elemento de la exposición de esa lógica de la Realidad, sino que - y ello es lo que le interesa últimamente a Hegel- ese momento abstracto-unilateral expresa una etapa inicial del despliegue del absoluto hacia la plena y total autoconsciencia de sí.

En segundo lugar, el aspecto dialéctico o negativamente racional. Este momento es, de algún modo, central para lograr una correcta interpretación de la Lógica de Hegel y, más en general, de toda su filosofía. Este momento es un paso ulterior al momento abstracto y consiste, en lo fundamental, en la supresión de la unilateralidad y la limitación de aquel momento por la puesta en marcha de determinaciones opuestas. Hegel caracteriza de esta manera el momento que tratamos: "el momento dialéctico es el suprimirse por sí dichas determinaciones finitas y su paso a las opuestas... En su carácter peculiar, lo dialéctico es... la propia y verdadera naturaleza de las determinaciones intelectuales de las cosas y de lo finito en general... La dialéctica es... esta resolución inmanente, 
en la cual la unilateralidad y limitación de las determinaciones intelectuales se expresan como lo que ella es, o sea como su negación. Todo lo finito tiene esta propiedad, que es suprimirse a sí mismo"(25). Y es por esta negatividad intrínseca a los fenómenos finitos por lo que éstos pueden desarrollares y explayar su naturaleza propia a lo largo de un proceso de desarrollo. La fuerza motriz de este proceso en devenir es la dialéctica interna que lo rige; su negatividad intrínseca.

Pero recordemos la parte dedicada a la dialéctica páginas atrás; en ella quedó establecido que la negatividad por antonomasia se encuentra en la historia social de la humanidad, en virtud, claro está, del elemento trabajo-praxis sobre el que aquélla se asienta. Sólo por este elemento se puede hablar de negatividad, de dialéctica, en sentido estricto. Cuando Hegel piensa en lo finito, piensa en lo finito histórico; en lo finito histórico que consiste en una multiplicidad de fenómenos y hechos empíricos, que van desde la praxis productiva, pasando por el arte y la religión, hasta la filosofía. A todos ellos, parcialmente o como totalidad, les es inherente la negatividad. Es de ellos, especialmente de los hechos históricofilosófico, de donde Hegel extrae los momentos esenciales de la lógica.

El propio Hegel ilustra este momento negativo-racional refiriéndose al progreso científico. Escribe al respecto: "la dialéctica forma, pues, el alma motriz del progreso científico, y es el principio por el cual solamente la conexión inmanente y la necesidad entran en el contenido de la ciencia; así como en ella, sobre todo, está la verdadera, y no exterior elevación sobre lo finito"(26). Porque la ciencia, tal como Hegel la entiende, es el conocimiento más elevado y profundo que de la necesidad o racionalidad intrínseca de las cosas finitas puede alcanzar el intelecto humano, así como la más verdadera interiorización en la estructura de lo finito. Pero este conocimiento cierto de la racionalidad interna de lo finitoreal no puede lograrlo la ciencia sin ella misma no haber recorrido el camino de la negatividad; ella misma, en tanto que hecho histórico-finito, debe pasar (y pasa) por el rodeo de la negatividad (así como por el de la simplicidad) para poder dar cuenta más cabalmente en épocas histórica superiores, en el caso que se trate de la ciencia histórica, de la necesidad inmanente al proceso histórico, y desde él a la Realidad en su Totalidad.

No es otra cosa lo que le sucede a Hegel con su Ciencia de la Lógica. Para intentar exponer en ella la racionalidad interna de la realidad, su lógica intrínseca, hubo que esperar, y asumir, todo ese largo camino de la historia de la filosofía que precedió a la filosofía hegeliana. Por tanto, el conocimiento científico —en tanto que fenómeno histórico- tiene como su fuerza motriz intrínseca la negatividad, la dialéctica. Pero ello es sólo un ejemplo. Es el ejemplo de la Ciencia hegeliana que "describe esa dialéctica real en su totalidad, así como la serie de filosofías consecutivas que corresponden a esa realidad dialéctica"(26), siendo movida a ella misma por la negatividad y siendo ésta la condición que hace posible tal conocimiento de la totalidad real. Con todo, si nos referimos a la historia real de 
la humanidad encontramos que ella se mueve no a fuerza de argumentos verbales, "sino a golpe de cachiporras y de espadas o de cañones por una parte, y de hoces y de martillos por otra... Es esa dialéctica histórica real la que se refleja en la historia de la filosofía"(27). Esa es la única manera de superar sus estadios iniciales; de superar su simplicidad y unilateralidad. Y la misma negatividad esencial se encuentra al estudiar cualquier hecho histórico.

Pero hay otro rasgo de gran importancia de esta determinación lógica que merece ser destacada aquí. Este rasgo es el carácter de fuerza motriz del desarrollo de los fenómenos que le compete al momento dialéctico-negativo. Este carácter de fuerza motriz del elemento negativo es el que posibilita la evolución, el desarrollo, de la cosa hacia su plenitud, hacia la diversidad de sus aspectos. Como escribe Hegel, "lo segundo es que lo en sí, lo simple, lo envuelto, se desarrolla, se desenvuelve. Desenvolverse quiere decir: ponerse, entrar a la existencia, existir como algo distinto... lo segundo es también que la existencia está en relación con otras cosas, que existe como algo diferente"(28); evoluciona, se enriquece, se hace más real. Este es el otro rasgo de la negatividad: ser una negatividad que enriquece. Pero es menester aclarar que este segundo momento, el momento negativo, no añade nada, por así decirlo, a lo real abstracto, es decir, el primer momento lógico: lo único que hace es abrir la realidad de éste a toda la riqueza de sus manifestaciones contenidas; mejor aún, ese momento negativo no es más que lo abstracto e indeterminado dinamizándose desde sí mimo a otro distinto de sí, pero ya contenido como posibilidad interna.

Esto es lo que quiere decir Hegel cuando anota que lo devenido en otro por la negatividad "es una y la misma cosa o más bien uno por el mismo contenido, ya exista en sí, envuelta [como cosa indeterminada], o como algo desarrollado. Es solamente una diferencia de la forma, pero de esta diferencia depende todo"(29); de ella depende todo el ulterior despliegue y planificación de la cosa real. En el caso de la Historia Humana en general, sólo por esa dialéctica que le es intrínseca puede el hombre, en el ámbito específico de la Historia de la Filosofía, alcanzar su máxima plenificación, el máximo conocimiento de sí y, con ella, el máximo grado de realidad. Igualmente, por la dialecticidad de la historia puede el Absoluto explayarse a plenitud y autoconocerse radicalmente en y por el conocimiento que el hombre logra de sí mismo, en y por el conocimiento que logra de la estructura Lógica de la Realidad y de sí en la filosofía y en su Historia. Como puede verse, la negatividad racional de la realidad es un momento ontológico y gnoseológico de gran importancia para Hegel.

Ontológicamente, le permite conceptuar un momento por el cual lo realhistórico deviene, se desarrolla y evoluciona hacia la plenitud concreta de sus múltiples determinaciones; y hacia la plena y total consciencia de sí del Hombre y del Absoluto a través del primero. Gnoseológicamente, es el momento posiblitante de la total apropiación conceptual por parte del hombre de la estruc- 
tura Lógica Esencial de la realidad que, en cuanto hecho histórico-real, se desenvuelve dialécticamente. En fin, esta racionalidad negativa es además que momento de lo Real-histórico condición de posibilidad de su conocimiento y autoconocimiento pleno. Es, además que momento del despliegue del absoluto, condición para que éste se autoposea plenamente. Se trata de dos procesos que, a una, constituyen el devenir de la Totalidad Real. "Así la historia de la filosofía y de la 'cultura' es en general un 'movimiento dialéctico', pero es un movimiento secundario y derivado"(30) del movimiento de la historia real de los pueblos; que son, asimismo, movimientos fundados en los movimientos lógicos del Absoluto. Sin embargo, es su unidad total la que da pleno sentido a la realidad y, por derivación, a la metafísica hegeliana.

En tercer lugar, el aspecto especulativo o positivamente racional. Este es otro momento importante tanto para conocer y conceptuar esencialmente la estructura de lo real como para aprehender la marcha misma del conocer humano hacia ella. Del lado de la Realidad, expresa un más alto grado de desarrollo, la culminación de su proceso evolutivo en una etapa superior de desarrollo, la síntesis de las determinaciones contrapuestas (dialéctica) del estadio anterior y la puesta en marcha, en un plano superior, de nuevas contradicciones y nuevos dinamismos. Del lado del conocimiento humano, expresa una etapa más elevada en la conceptualización de la estructura de la realidad y en el propio conocimiento que el hombre logra de sí y del lado del autoconocimiento y devenir del Absoluto expresa grados más altos de realización y de autoconciencia.

Hegel, en la Enciclopedia, caracteriza de este modo el momento especulativo: "el momento especulativo o el positivo racional, concibe la unidad de las determinaciones en su oposición; y es lo que allí hay de afirmativo en su solución y en su superación"(31); por lo cual representa un momento más rico del devenir de lo Real, ya que implica una superación de los opuestos, así como la conservación de lo más positivo de ambos, y un momento más rico en lo que respecta al conocimiento que el hombre pueda tener sobre ello; en ese caso se aprehende mayor densidad de realidad. Por tanto, este momento especulativo racional lleva inscritos dos aspectos esenciales que expresan su riqueza ontológicognoseológica: expresa mayor densidad de realidad en cada nuevo plano superior de síntesis y expresa un conocimiento más profundo de la realidad, un conocimiento más radical y último.

Como dice Hegel, "este racional es, por lo tanto, aún siendo algo pensado y abstracto, a la vez algo concreto, porque no es unidad simple y formal, sino unidad de determinaciones diversas"(32); y por ser un pensamiento que manifiesta esa unidad de determinaciones en la que se sintetizan las contradicciones es un pensamiento Concreto. Es decir, un pensamiento que expone, luego de haberla extraído del devenir real-histórico, la estructura lógico-racional de esa realidad en devenir. La categoría expuesta es, en este sentido, un pensamiento 
concreto. Expresa doblemente mayor riqueza de realidad y un conocimiento más total de la misma. Y este vale para cualquier realidad, ya sea en su especificidad o ya sea en su totalidad. Las cosas particulares, en sus momentos de síntesis, se enriquecen mucho más (aunque sean síntesis transitorias y perecederas) al alcanzar niveles de desarrollo más elevados; la totalidad de la realidad, igualmente, en su proceso de desarrollo se eleva a planos superiores en cada momento en que se sintetizan sus contradicciones, en cada momento de "superación" y de "conservación" de sus opuestos.

Paralelamente, el conocimiento humano cada vez que capta y conceptúa esos momentos de síntesis, capta y conceptúa mayor realidad; capta y conceptúa mayor esencialidad real y, consiguientemente, mayor conocimiento de sí mismo y del absoluto. Si se ve esto desde el absoluto, hay que decir que éste, en las fases de Aufheben, de superación-que-conserva, logra mayor concreción, mayor realización y, por tanto, mayor conocimiento de sí. Metafísicamente, Hegel — para destacar el rango de realidad que manifiesta ese momento positivo-racional- lo llama Ser Para Sí, el ser de una realidad en planos superiores de desarrollo y autoposesión; en planos de desarrollo más concretos y multideterminados; en planos, en fin, en los que se hayan subsumidos los momentos anteriores. Juntando los tres momentos que hemos analizado (lo abstracto, lo negativo y lo racional) y caracterizando al tercero de ellos, escribe Hegel: "el primer momento era lo en sí de la realización, lo en sí del germen, etc.; el segundo es la existencia (Dasein), aquello que resulta; así, es el tercero la identidad de ambos, más precisamente, ahora, el fruto de la evolución, el resultado de todo este movimiento; y a todo eso llamo yo abstractamente, el Ser por sí [el Ser para sí1]"(31).

El Ser para si es, por tanto, la totalidad de determinaciones de un hecho real-histórico, sintetizadas procesualmente desde un ser abstracto, en sí, pasando por un ser en otro, la negatividad, la existencia, hasta su recuperación como un ser para sí, su autoposesión. Y esto, siendo propio de la Historia Universal en su conjunto, encuentra su manifestación por excelencia en la historia del pensamiento filosófico, que es de donde, en lo fundamental, han sido extraídos los momentos lógicos señalados. Como escribe Hegel, el ser para sí "es el ser por sí del hombre, del espíritu mismo; pues la planta no tiene ser por sí (ser para s1), sino en tanto que hablamos un lenguaje que se refiere a la conciencia. Solamente el espíritu llega a ser verdadero por sí, idéntico consigo mismo"(34); solamente en la historia humana - más precisamente en la historia de la filosofíase llega a manifestar propiamente lo para sí.

Pero también este momento especulativo racional tiene una dimensión Gnoseológica que es preciso destacar. Y es que para Hegel ese momento de lo real-histórico sólo puede ser captado por un conocimiento superior, es decir, por el conocimiento filosófico. Mejor aun, no solamente puede ser captado por el pensar filosófico-racional, sino que su exposición misma como momento lógico, 
como categoría Lógica, corre por cuenta de la filosofía. El momento especulativo-racional es aprehendido y expuesto por la filosofía. Como dice Hegel, "en la lógica especulativa está contenida la mera lógica del intelecto que puede ser sacada de aquélla; no hay que hacer otra cosa que dejar caer el elemento dialéctico y el racional; así llega a ser lo que es la lógica ordinaria: una historia, o sea una descripción de varias determinaciones del pensamiento puestas juntas, y que en su finitud se toman por algo infinito"(35). En otro texto, insiste Hegel: "es un concepto especulativo, esta unidad de lo diferente, del germen y de lo desarrollado; esas cosas son dos y, sin embargo, una. Es un concepto de la razón; por eso sólo las otras determinaciones son inteligibles. Pero el entendimiento abstracto no puede concebir esto; el entendimiento se queda con las diferencias, sólo puede comprender abstracciones, no lo concreto, ni el concepto"(36).

Cuando se ha llegado a la etapa de producir conceptos, el hombre está a las puertas de conocer plenamente la realidad, de conocer al Absoluto, de conocerse a sí mismo y, finalmente, de convertirse en una realidad para sí plena. El Absoluto, en esta línea de reflexión, a medida que se lleva a cabo el proceso descrito hacia el para sí humano, gana en auto posesión y autoconciencia de sí; se vuelve él también realidad para sí en y para el ser para sí del hombre, del espíritu .

Hemos visto los momentos fundamentales del discurso lógico. Queda por examinar las categorías lógicas (ontológicas) que dan mayor sentido teórico y real a los momentos ya explicados. De manera global, expondremos las categorías fundamentales de la Lógica, dividida por Hegel en tres partes: la Doctrina del Ser, la Doctrina de la Esencia y la doctrina del concepto. Pero antes volvamos una vez más, al carácter de la Logik. Para ello veamos el siguiente texto de Hegel. "Por lo tanto —nos dice-, hay que concebir la Lógica como el sistema de la razón pura, como el reino del pensamiento puro. Este reino es la verdad, tal como ella es, sin velo, en sí y para sí y para sí misma. Puede, por lo tanto, decirse que este contenido es la manifestación de Dios, tal como él es en su eterna esencia, antes de la creación de la naturaleza y de un espíritu finito"(37).

Pero, hay que repetirlo una vez más, es el sistema de la razón pura abstraído del devenir de la totalidad real; luego de haber estudiado todo su proceso de desarrollo. Un sistema que si bien expresa conceptualmente lo esencial de la realidad anteriormente a todo desarrollo empírico no se hubiese constituido como tal sistema sino por el despliegue y la explanación de esa realidad esencial bajo una forma empírico-concreta.

\section{Estructura de la Lógica}

A. Categorías fundamentales del ser: cualidad, cantidad y medida

En la primera sección de la lógica, titulada la Doctrina del ser, aparecen tres categorías básicas y fundamentales sobre el mismo. La cualidad, la cantidad y la medida. Examinémoslas someramente. 
a) Cualidad. Esta categoría está conformada, por así decirlo, por las subcategorías de ser en sí, ser determinado (Dasein) y ser para sí. De alguna manera, en lo dicho páginas atrás ha quedado bastante claro el significado de cada una de esas subcategorías. Lo que pretendemos ahora es puntualizar el carácter unitario de esos tres momentos en la categoría de cualidad. Pues bien, para Hegel la cualidad, siendo la unidad de esos tres momentos, es lo que determina el carácter de una realidad dada como distinta radicalmente a otra. Es en la acepción más rigurosa del vocablo "ser para sí". Expresa la realización más plena de una determinada realidad; esa realidad ha alcanzado un perfil propio relativo a las demás cosas y a sí misma. Como escribe Hegel: "El ser para sí, como relación consigo mismo, es inmediatividad, y como relación de lo negativo consigo mismo, es lo que es para sí lo uno; lo que por ser diferenciado en sí mismo excluye lo otro"(38). Es justo esta diferenciación de sí respecto de lo otro, así como la propia inmediatez, lo que hace a una realidad cualitativamente distinta de otra; radicalmente distinta de ella. Y, recordémoslo, una determinada realidad sólo alcanza la plenitud de sí —l desarrollo pleno de sus determinaciones, su máxima concreción ontológica-, cuando ha alcanzado el estadio de realidad para sí. Es en ese momento cuando la cosa se constituye como Una; como una cosa diferenciada y contradistinta de las demás. Ser una realidad Propia, Unitaria, es la que cualifica a una realidad. Por ello, la categoría de Cualidad es, más que expresión teórica (lógica) de la Realidad, del Ser, un momento constitutivo del mismo: el momento por el cual una realidad es esta y no otra; es el Ser para Sí de ella internamente cualificado y especificado.

b) Cantidad. Esta es la segunda categoría Lógica-Ontológica constitutiva a la que el filósofo tiene que remitirse para dar cuenta de la estructura del Ser. Ella permite caracterizar al Ser como cantidad; como ocupando un lugar espacio temporal, con unas determinadas dimensiones. Su rasgo esencial es que, dentro de unos límites, sus modificaciones no alteran la estructura cualitativa del ser de lo real. Tal es el caso de la Magnitud. Esta propiedad cuantitativa de lo real —cuantitativa porque hace referencia a un aspecto puramente físico - es la que sirve a Hegel para aclarar su idea de lo que es la categoría de cantidad. En la Enciclopedia señala: "la matemática suele definir la magnitud como lo que puede ser aumentado y disminuido... la determinación de la magnitud es tal, que es puesta como mudable e indiferente, de modo que, no obstante sus mutaciones, un aumento de intensidad o de extensión, la cosa, por ejemplo, una cosa o el color rojo, etc., no deja de ser una casa o color rojo"(39). Es decir, la magnitud física de una realidad, no obstante sus mutaciones ya sean en intensidad o extensión - y dentro de unos limites físicos precisos- no altera su carácter cualitativo. Este aspecto físico medido como magnitud es justamente la cantidad de una cosa, su momento cuantitativo. 
Sin embargo, la cantidad no se agota ni mucho menos con lo dicho. En ella, Hegel distingue tres momentos básicos y constituyentes, a saber: la cantidad pura, el cuanto y el grado. Describámoslo brevemente.

En primer lugar, la cantidad pura. Este momento cuantitativo es, de algún modo, el que caracteriza al momento cualitativo del ser en sí. Y consiste en una indeterminación de la magnitud física en cualquiera de sus aspectos. "Lo absoluto - escribe Hegel- es pura cantidad: este punto de vista coincide en general con aquello que da a lo absoluto la determinación de materia, en la cual existe ciertamente la forma, pero es una determinación indiferente. También la cantidad constituye la determinación fundamental de lo absoluto cuando es concebida de modo que en él, en lo absolutamente indiferente, toda diferencia es sólo cuantitativa. Por lo demás, el espacio puro, el tiempo, etc., pueden ser tomados como ejemplos de la cantidad, si lo real es concebido como llenando indiferentemente el espacio y el tiempo"(40). Es decir, que tomado lo real en su indiferenciación cualitativa, como ser en sí, se tiene, igualmente, una cantidad indiferenciada e indeterminada; una cantidad pura. Hegel escribe al respecto: "la cantidad es el puro ser en quien la determinación es puesta, no ya como una con el ser mismo, sino como superada e indiferente"(41). Esta determinación cuantitativa "indiferente" (y, por tanto, estrictamente indeterminada) es la cantidad pura, que, como tal, se identifica con lo Absoluto indiferenciado: se trata del puro ser, que es igual a la pura cantidad.

En segundo lugar, el cuanto. Este momento cuantitativo hace referencia a una magnitud ya no indiferente - como era el caso de la cantidad pura-, sino una magnitud discreta, finita, limitada. "La cantidad puesta esencialmente con la determinación exclusiva que en ella está contenida - dice Hegel—, es el cuanto, la cantidad limitada"(42). Esto es, que la realidad adquiere estatus físico de cuanto, solamente cuando sus magnitudes físicas propias han comenzado a diferenciarse; cuando la cantidad en ella contenida ha mostrado sus determinaciones. En ese momento, en el momento en que la propiedad cuantitativa de una realidad se determina y diferencia, es cuando la cantidad se vuelve cuanto: se vuelve una cantidad limitada. Los números, cree Hegel, son la determinación y desenvolvimiento de este elemento de la cantidad. "El cuanto - dice Hegeltiene su desenvolvimiento y su completa determinación en el número, que teniendo como elemento propio lo uno, contiene en sí... la multitud o número particular... [y] la unidad que son los elementos cualitativos de lo uno"(23). Por otro lado, no hay que dejar de decir que, de alguna manera, este momento de cuantificación de la cantidad corresponde al momento cualitativo del ser determinado. Porque sólo cuando una realidad ha mostrado en el proceso de su desarrollo sus internas determinaciones, en virtud de la negatividad, se puede encontrar en ella (porque ella lo muestra) su momento cuántico. Por tal razón hay que afirmar que el momento Lógico-Ontológico del ser determinado del cuanto está en unidad indisoluble con el momento Lógico-Ontológico del Ser determinado;

\section{0}

Realidad 85, 2002 
igualmente, están en unidad inseparable la Cantidad Pura y el Ser en Sí; y, en general, tal como están en unidad lo cuantitativo y lo cualitativo.

Esta unidad, en tercer lugar, se expresa en el grado. Este es el otro momento de la cantidad al que hay que prestar atención. En él se hayan ligados unitariamente los momentos cualitativos y cuantitativo de la realidad. Claramente lo apunta Hegel cuando dice que "en él [en el grado] se hayan reunidos la exterioridad, es decir, lo cuantitativo y el ser para sí, es decir, lo cualitativo"(44). Por tanto, en el momento Lógico-Ontológico de grado lo que se tiene es la unidad del Ser para Sí (la cualidad de la cosa realizada plenamente) y de la exterioridad (lo cuantitativo bien determinado). Y para articular lo que estamos diciendo con lo anterior, anotemos que el grado es la exterioridad del Cuanto, pero una exterioridad cualificada. Es por ello por lo que se puede expresar la unidad de lo cualitativo y de lo cuantitativo en este momento de grado. Como escribe Hegel, "esta exterioridad del cuanto en su determinación, determinabilidad en sí mismo, constituye su cualidad; esta exterioridad es precisamente lo que es y está en relación consigo mismo"(45). Es en este sentido que el grado muestra y, mejor aún, constituye la unidad cantidad-cualidad. Manifiesta, por esto, tanto el nivel más elevado de la cantidad, como el nivel más elevado de la cualidad, en una síntesis que los asume y supera.

En resumen, entre cantidad y cualidad (ambos momentos ontológicos y lógicos de lo real) hay una unidad intrínseca que se expresa en las conexiones que se dan entre ambas categorías. Así, hay una correspondencia entre Ser en sí y Cantidad pura, entre Ser determinado y Cuanto y entre Ser para sí y Grado. Pero, en general, el vínculo estructural que los une es lo cuantitativo y lo cualitativo tomados como totalidad. El grado es expresión de esta unidad. Sin embargo, la expresión más acabada de dicha unidad se capta en la tercera Categoría del Ser que señalamos antes: la Medida.

c) Medida. De entrada, en la Enciclopedia, Hegel define lo que es la medida. $\mathrm{Al}$ respecto escribe: "la medida es el cuanto cualitativo, primero como inmediato, un cuanto al cual está ligado un ser determinado o una cualidad"(46); cosa que se parece mucho a lo que ya hemos dicho sobre el grado, $Y$ no es por casualidad. De hecho, la categoría de medida subsume dentro de sí al momento de grado; por lo cual es en ella en donde aparece con mayor nitidez el vínculo unitario entre lo cuantitativo y lo cualitativo. Pero la medida no es sólo un cuanto cualificado, ni tampoco es sólo la unidad inmediata de cualidad y cantidad. Lo más propio de ella consiste en que expresa los límites cuantitativos —en cambios y modificaciones- que una realidad internamente cualificada puede soportar y seguir siendo la misma realidad.

No es otra cosa lo que Hegel quiere decir cuando escribe que "el cuanto específico [la magnitud cuantitativa determinada de una cosa] es, por consiguiente, en parte un simple cuanto; y el ser determinado capaz de aumento y 
disminución, sin que la medida, la cual es una regla, sea por esto suprimida; pero, en parte, el cambio del cuanto es también un cambio de la cualidad"(47). ¿Qué está diciendo Hegel en estas líneas? Está diciendo dos cosas, en lo fundamental.

Primero, que la medida es una regla; una regla que limita y que registra los cambios cuantitativos que una cualidad determinada puede aceptar (dicho antropomórficamente) y seguir siendo esa misma cualidad; una regla que mide, que mensura, las posibilidades de cambio cuantitativo de una determinada estructura cualitativa, que al ser sobrepasado daría paso a otra cualidad radicalmente distinta, así como a otra medida, a otra regla, que correspondería a la nueva estructura cualitativo-cuantitativa instaurada. Segundo, está diciendo, también, que de algún modo las variaciones cuantitativas que admiten una cualidad dada conllevan un cambio sobre ésta; aunque no radical. O sea, pues, que la cualidad propia de una cantidad no es estática, sino que es dinámica, marcando la pauta de estos dinamismos los cambios cuantitativos, tanto dentro de una misma cualidad como de cualidad a cualidad.

Por otra parte, además de los puntos extraídos de la cita de Hegel, podemos dejar apuntadas dos ideas que nos salen al paso. En primer lugar, que la Realidad, el Ser, es para Hegel intrínsecamente dinámico; cosa ya admitida a propósito de la dialéctica hegeliana. En segundo lugar, que para Hegel la realidad en su totalidad, así como en sus momentos particulares, está conformada estructuralmente. Lo cuantitativo y lo cualitativo, como momentos de lo real, no son más que expresión físico-material (la primera) y organizativa-específica (la segunda) de esa estructuración. Más aún, una cantidad y una cualidad determinadas, además de corresponderse recíprocamente en una determinada realidad, son la cantidad y la cualidad de esa realidad, y no de otra.

Con lo dicho hemos caracterizado a grandes rasgos las tres categorías fundamentales del Ser: la cualidad, la cantidad y la medida. Son tres categorías esenciales de la estructura lógica de lo real y de la conceptualización teórica de la misma. Son, por ello, tres momentos Lógico-Ontológicos de la Realidad, del Ser. Son, Asimismo, tres momentos unitaria y dinámicamente estructurados en orden a la procesualidad de lo real, y juntos caracterizan lo que Hegel llama el Ser: el En sí, el Ser determinado y el Ser para sí. Para finalizar, citemos el texto de Hegel con el que inicia la primera sección de la Lógica, ya que en el mismo se sintetiza lo que venimos apuntando. "El Ser es el concepto puramente en sí; las determinaciones del ser, en cuanto son (Seiende) y en su distinción opuestas a otras; su determinación ulterior (la forma de la dialéctica) es un pasar a otras. Esta ulterior determinación es, a la vez, un ponerse exteriormente, y con ello un desarrollarse del concepto que era primero en sí (des an sich seinenden Begriffs) y a la vez el ir así (Insichgehen) del ser, un sumergirse de éste en sí mismo. El desarrollo del concepto en la esfera del ser se hace la totalidad del ser; al mismo

\section{2}


tiempo la inmediatividad del ser o la forma del ser, como tal, es suprimida (aufgeheben)"(48). La cantidad, la cualidad y la media son tres momentos esenciales de ese desarrollo del ser, como concepto, en la esfera de la totalidad del ser. El En sí, el Ser determinado y el Ser para sí son los tres estadios cualificantes del ser, a través de los cuales éste marcha hacia su plena realización.

Por tanto: Cualidad, Cantidad y Medida, por un lado, y Ser en sí, Ser determinado y Ser para sí, por otro, son determinaciones momentuales del Concepto de Ser abstraídas del desarrollo Histórico-Real y expuestas, como determinaciones conceptuales, por el intelecto filosófico, al igual que el propio concepto del Ser. Este no es otra cosa que un momento esencial de la totalidad de lo real captado en y a través del desarrollo empírico de esta totalidad, que es expuesto por el filósofo desde su despliegue inicial, pero en su movimiento puro, como concepto. De más está decir que, en su despliegue real y efectivo, el Ser está recubierto de las formas empíricas más variadas; y que su movimiento de Puro ser a Ser empírico ha sido dinamizado por el antagonismo Nada-Ser. Justamente por ello la tarea del filósofo consiste, y ha consistido — según Hegel— en descubrir ese movimiento lógico-esencial del Concepto bajo su caparazón empírica-accidental y exponer

lo tal y como subyace en el fondo de los procesos concretos-empíricos. Claro está, ello sólo es posible en la culminación dialéctica de los procesos.

\section{B. Categorías fundamentales de la esencia: existencia, fenómeno y realidad}

En la segunda sección de la lógica, llamada la Doctrina de la esencia, Hegel se propone estudiar las llamadas por él categorías de la reflexión. Apuntemos rápidamente lo que Hegel entiende por esencia y por reflexión, y luego presentemos las categorías señaladas.

Para Findlay, "la esencia es la antítesis de lo que en ella salta inmediatamente a la vista: es algo que se encuentra detrás o dentro de la superficie inmediata de la apariencia, y que sólo se alcanza cuando de penetra por debajo de ésta"(49). Es decir, que esencia es lo que está tras la apariencia, tras lo que aparece. Ahora, hay que preguntarse por el carácter mismo de la penetración mencionada: la misma consiste en reflexionar. "Tal penetración —nos dice Findlay - es reflexiva, y los objetos hasta los cuales penetra son postulados o puestos, inferidos y mediados, más bien que dados"(50). Esto es, la reflexión penetra hacia un ámbito (el esencial) oculto, no dado exteriormente, y que sólo puede ser aprehendido en cuanto a través de mediaciones. "La esencia —dice Hegel— es el concepto en cuanto concepto puesto... Le esencia, como el ser mediado consigo mismo por la negación de sí mismo, es la referencia a sí mismo en cuanto referencia a otro; pero este otro, no como siendo inmediatamente, sino como algo puesto y mediado... La esencia es, por tanto, como un aparecer en sí mismo"(51); como un aparecer en sí mismo del ser. Un aparecer en sí que, por 
la dialéctica propia que le compete al ser, no es un salir fuera de él. Muy por el contrario implica un subsumirse dentro de sí.

Y es que la negación de sí del ser en que consiste la esencia, la negación de sí como algo dado, no es algo exterior al ser mismo, sino que constituye su propia dialéctica, su verdad. Es por ello que la esencia no solamente es una conceptualización de carácter teórico añadida a la Realidad, sino que es un momento ontológico de ella; un momento ontológico que se muestra sólo por la reflexión, es decir, que se distingue del ser inmediato, con el que forma una unidad, por la reflexión que es la determinación de la esencia misma. Para Hegel, "la negatividad no es exterior al ser, sino que constituye su propia dialéctica, es, por tanto su verdad, la esencia como el ser que ha penetrado en sí mismo o que es en sí mismo; su distinción del ser inmediato está constituida por aquella reflexión, por su aparecer en sí mismo y ella es la propia determinación de la esencia misma"(52).

En suma, para Hegel, la Reflexión y la Esencia son dos momentos indisolublemente ligados; con lo que nos sale otra vez el tema de la unidad entre lo lógico y ontológico. La esencia, como momento fundamental de lo real y como momento expresado por el intelecto reflexivo, muestra palmariamente dicha unidad. Las categorías de la esencia que a continuación trataremos son, a la vez que momentos del ser, momentos de la reflexión; momentos de los que ésta se vale para exponer lo esencial-lógico de la realidad en su estado puro.

Categorías de la esencia: 1) existencia (compuesta por los siguientes momentos: identidad, diferencia, semejanza, oposición y contradicción); 2) fenómeno (compuesta por los siguientes momentos: mundo del fenómeno, contenido y forma, y relación); y 3) realidad (compuesta por los siguientes momentos: lo real, lo posible, lo contingente y lo necesario)(53).

\section{i) La existencia}

La categoría de Existencia consta de los momentos que a continuación expondremos.

a) Identidad. Esta categoría tiene para Hegel el mismo rango ontológico que tiene respecto del Ser la categoría de Puro Ser. "Identidad es la noción inmediata - escribe Findlay-, no desarrollada, de lo que es esencial, lo mismo que el ser puro es la forma inmediata a partir de la cual se desarrollan luego Cantidad y Cualidad" (54). O, como dice el propio Hegel, "esta identidad es identidad formal o sea del intelecto, en cuanto se detiene en ella y se abstrae de la diferencia, o más bien, la abstracción es el poner esta identidad formal, la transformación de una cosa en sí concreta en esta forma de la simplicidad, ya que se prescinde de lo múltiple existentes en concreto...; ya sea que, abandonado sus variedades, se reúnan en una de los múltiples determinaciones"(55). Porque, en definitiva, cuando Hegel habla de la esencia piensa en 
ella como en una realidad "elaborada" por la reflexión. El texto citado lo que hace es destacar esa problemática. Por ello dice Hegel que la "identidad" es una identidad del intelecto; es, si se quiere, una fase, inicial por cierto, de la marcha del intelecto reflexivo hacia la esencia; una fase en la que se simplifica la realidad obviando la totalidad de sus determinaciones, y reduciéndola a una determinación concreta.

b) Diferencia. Este momento constituye un segundo aspecto de la reflexión, que está inseparablemente ligado al concepto de la identidad. Desde el punto de vista de la cosa real, la Diferencia es un momento de ella situado a un nivel menos profundo que el momento de Identidad. Es decir, la identidad toca más de cerca la estructura íntima de la cosa real. Como apunta Findlay, "esta diferencia es, en primer lugar, una diferencia de la superficie, así como la identidad es una identidad a nivel más profundo. Es obvio que las cosas sólo pueden ser idénticas en esencia si pueden ser superficialmente diferentes, y viceversa"(56).

El problema de la diferencia, por otro lado, también se puede ver desde la reflexión. Y visto desde ella, la Diferencia es una diferencia de esencia, y no simplemente una diferencia superficial. "Desde el concepto reflexivo de Identidad -nos dice Findlay-, Hegel avanza dialécticamente el concepto reflexivo de Diferencia (Unterschied), que no es, sin embargo, la diferencia superficial antes considerada, sino una diferencia de esencia"(57). Y Hegel, en la Enciclopedia, hace justo la distinción que nosotros, con Findlay, hemos hecho. En las cosas reales, dice Hegel "la Diferencia es: Diferencia inmediata, la diversidad en la cual los distintos son cada uno de por sí lo que son, y son indiferentes en su referencia a otros, referencia que por lo mismo es extraña a ello... Esta diferencia exterior, como identidad de lo referido, es igualdad; como no identidad es desigualdad"(58). De cara a la reflexión, la Diferencia ya no es propiamente una Diferencia Inmediata, sino una Diferencia de Esencia, una diferencia negativa. Como escribe Hegel: "la diferencia en sí es la diferencia esencial, lo positivo y lo negativo: lo positivo es la relación idéntica a sí misma de modo que no es lo negativo, y esto es lo diferente por sí, de modo que no es lo positivo"(59). Más clara es aún la caracterización de la diferencia de cara a la reflexión: "la diferencia de la esencia es, por tanto, la contraposición, según la cual lo diferente no tiene frente así un otro en general, sino su otro; esto es, cada uno tiene su propia determinación sólo en relación con el otro; es reflejado en sí sólo en cuanto es reflejado en el otro, e igualmente el otro; cada uno es, de este modo, su otro del otro"(60). Este "otro", en el que cada uno encuentra su propia determinación, por contraposicón reflexiva, nos da la diferencia esencial de la cosa contrapuesta; es, en este sentido, una diferencia esencial de índole intelectual-reflexivo, pero fundada en una diferencia real. 
c) Semejanza-Desemejanza. Estos dos conceptos son claves en lo que toca al problema de la esencia y sus categorías. Para Findlay, el concepto de Semejanza significa identidad precisa en algún carácter más bien que mera similitud (61); por lo que, de alguna manera, la categoría de semejanza nos remite a la de Identidad. Y es que como anota el autor citado, "la semejanza es una identidad atenuada puesta sólo en una reflexión externa sobre cosas intrínsecamente indiferentes"(62). Lo mismo dígase de la categoría de Desemejanza; ella remite a la diferencia. "La desemejanza es, asimismo - apunta Findlay-, una diferencia externa, no idéntica con la esencial 'Diferencia' que es la fuente del ser distintivo de una cosa”(63). Por tanto, Semejanza y Desemejanza hacen referencia a dos momentos de la exterioridad de una cosa real en el ámbito de su esencia. La Semejanza es una Identidad 'atenuada', es decir, una identidad insinuada, no realizada ya que en tal caso sería plena identidad. La Desemejanza es una Diferencia igualmente 'atenuada', porque en caso de ser una Diferencia plena, es decir, una diferencia esencial, sería la fuente del ser distintivo de una cosa; y la desemejanza no llega a eso: es solamente una diferencia Externa, no interna.

Por ello, si hay coincidencias entre Semejanza e Identidad y entre Desemejanza y Diferencia, son solamente coincidencias exteriores: a lo sumo, coincidencias derivadas de la relación de fundamentación en que se encuentran las categorías de identidad y diferencia respecto a las de semejanza y desemejanza. Lo que sin embargo es cierto es que cada una de ella expresa niveles distintos de reflexión esencial. Incluso, entre las de semejanza y desemejanza se da una precisa articulación en orden a la reflexión. Según Findlay, Hegel inicia el profundo y obvio ensamblaje de estas dos últimas nociones, cómo la posición de Semejanza sólo tiene lugar significativamente sobre el fondo de la Desemejanza, y viceversa(64)

d) Oposición. Este momento, llamado también Oposición Polar, no recibe en la Enciclopedia un tratamiento detallado. Por ello nos centraremos en las ideas que Findlay plantea en su libro Reexamen de Hegel, desde el cual caracterizaremos el concepto mencionado. Para Findlay, en la Ciencia de la Lógica, Hegel explica el carácter de esta Oposición Polar. En esta obra, "Hegel indica cómo el entendimiento trata de convertir Semejanza y Desemejaza en Identidades y Diversidades absolutas... Así congeladas, Semejanza y Desemejanza pierden su esencial pertinencia mutua, que les da color y significado: se transforman en un caso de diferencias que no son diferencias, y ése, para Hegel, es el carácter esencial de la Oposición Polar"(65).

En este sentido, se tiene oposición al nivel de reflexión cada vez que el intelecto absolutiza ya sea a la semejanza, convirtiéndola en identidad, ya sea a la desemejanza, convirtiéndola en diferencia. Son oposiciones de 'sentido', como diría Hegel, Pero son oposiciones, asimismo, fundadas en un carácter físico de 
lo real considerado esencialmente. El mismo Hegel, citado por Findlay, escribe lo siguiente: "en la Oposición la cosa se distingue como no meramente otra, sino como su otra en contraste con ella. La consciencia común trata los diferentes como indiferentes unos a otros. Uno dice: yo soy hombre y a mi alrededor hay aire, agua, animales, y otras cosas en general. Todo que aparte. Contra eso, el objetivo de la filosofía es desterrar la indiferencia y reconocer la necesidad de las cosas, de modo que lo otro aparezca enfrentado a su otro"(66). Se tiene que captar el entrenamiento, las oposiciones, de unas cosas con otras; los diferentes no como indiferentes, sino como interconectados por sus mutuas oposiciones. Porque, en definitiva, es en este oponerse mutuo, en este enfrentarse de lo uno con lo otro, en donde radica para Hegel la fuerza dinamizadora de la realidad. Y ello, por ser un momento físico-metafísico de lo real, es un momento constitutivo del proceso de intelección humana. Esta también atraviesa un movimiento dialéctico, mejor dicho es dialéctica en esencia. El momento de las Oposiciones a que nos estamos refiriendo es un hecho necesario y posiblitante de la intelección de la esencia de lo real. A medida que la realidad se va moviendo dialécticamente, el intelecto va captando y exponiendo ese movimiento que, como parte de la realidad que es, manifiesta y soporta. Todo ello en el marco de una misma unidad.

e) Contradicción. Este concepto está estrechamente ligado al de Oposición; de algún modo lo subsume dentro de sí. En la Ciencia de la Lógica, la idea de contradicción sintetiza la identidad y las distintas formas de diferencia, mientras que en la Enciclopedia no está separada de esta última (67). Veámosla con cierto detalle.

En primer lugar, la Contradicción $\longrightarrow$ la negatividad- es un momento ontológico de lo real, del ser; pero es, asimismo, un momento de la reflexión sobre esa realidad esencial. Y es justo este el sentido de la contradicción al que estamos haciendo referencia: la contradicción como momento de la reflexión lógico esencial. Pues bien, vista así, la contradicción es resultado del desarrollo de la Oposición polar. Como dice Hegel, "cuando reflexionamos sobre el hecho de que cada opuesto debe en cierto sentido contener, y también no contener, a su opuesto: cada opuesto es mediado consigo mismo a través de su otro, y así contiene a este, pero es también mediado consigo mismo a través del no-ser de su otro, y a través de la exclusión del otro de sí mismo" (68).

Veamos esto por partes. Primero, según Findlay, hay un nivel de reflexión contradictorio cuando se aborda un hecho, un fenómeno, opuesto a otro, y se piensa que debe contener y no contener, en sí, al hecho que se opone, a su opuesto. Segundo, desde Hegel, cada hecho opuesto a otro es mediado por este otro, tanto por lo que es en sí como por lo que no es. Donde mediado significa que está atravesado por el otro, que lo lleva dentro de sí. Reflexionar sobre ello es reflexionar contradictoriamente. Más aún, "es en el intento de dar separación 
e independencia a las determinaciones opuestas donde surge la contradicción: la contradicción es pues el límite hacia el cual tiende toda diferencia y oposición" (69); la reflexión esencial es el camino hacia la síntesis especulativa. Hay que dejar taxativamente anotado que, para Hegel, la contradicción expresa un momento de la estructura lógica en su totalidad, expresa un momento de la estructura Lógico-Ontológica del Ser. No sólo es un hecho de reflexión intelectiva. Más aún, la reflexión intelectual es contradictoria tanto porque es parte de la realidad como porque "refleja" la contradictoriedad misma de lo real(70), esto es, su dialecticidad interna. En general, sólo porque el intelecto humano trasluce las estructuras dialécticas de la realidad es por lo que es dialéctico, en cuanto intelecto.

\section{ii) El Fenómeno}

a) Fenómeno. Este concepto lógico-ontológico tiene gran peso dentro del pensamiento hegeliano ya que vincula tanto la índole esencial con lo que aparece, como porque abre el horizonte a las posibilidades de conocimiento de esa esencia por parte del hombre. Hegel caracteriza al Fenómeno así: "la esencia debe aparecer. Su aparecer es en ella el suprimirse a sí misma haciéndose inmediatividad... El aparecer es la determinación, por medio de la cual la esencia no es ser si no esencia, y el aparecer desarrollado es el fenómeno"(71). En la Enciclopedia, continúa Hegel: "ambos momentos son las determinaciones peculiares de la esencia misma, y constituyen esta esencia"(72). Por tanto, de lo dicho se desprenden dos cosas: en primer lugar, que la esencia, en virtud de su movimiento interno (negativo) se suprime haciéndose inmediatividad, trastocándose en su contrario, apareciendo; en segundo lugar, que fenómenos y esencia conforman una unidad; mejor aún, el fenómeno es un momento de la esencia, su momento de exterioridad. Por ello es que el fenómeno, el ser fenoménico, se opone a la mera apariencia. Es un Ser que vehicula la interioridad de lo real. Es un Ser que ha salido del fundamento y que, en virtud de ello, existe(73).

De lo dicho, por otra parte, se desprende que ese vínculo real de fenómeno y esencia, del ser fenoménico y del ser esencial, es el que hace posible acceder a la esencia. Finalmente, anotemos que esta realidad fenoménica aparece infinitamente mediada en la Existencia por la Forma. "Esta mediación infinita -escribe Hegel- es al mismo tiempo unidad de la relación consigo misma, y desarrolla la existencia, haciendo de ella una totalidad y un mundo del fenómeno de la finidad refleja"(74). El fenómeno y el ser esencial, en unidad con las formas empírico-concretas de las que ambos se revisten, constituyen la totalidad de la existencia, la totalidad del mundo del fenómeno.

b) Contenido y Forma. De alguna manera ya fue insinuado lo que entiende Hegel por Forma. Puntualicemos su significado y luego atendamos al Conte- 
nido. La forma, ya se dijo, muestra la existencia empírico-concreta del fenómeno, no confundiéndose con él. La Forma es un momento del fenómeno: lo que aparece, pero que es mudable, perecedero, lo que no expresa conexión intrínseca con la esencia. Como anota Hegel: "en la Forma, como no reflejada en sí, está el lado negativo del fenómeno, lo que hay en él de relativo y mudable: es la forma indiferente, externa" (75). Pero el fenómeno tiene su lado positivo; es el fenómeno como reflejado en sí. Es el Contenido. Este es otro momento del fenómeno, el momento de su realidad interna: lo que subyace tras la forma. Y entre ambos (Contenido y Forma) hay una configuración antitética: la Forma expresa y oculta al Contenido; éste niega la forma, pero es mediado por ella. Según Hegel, "tenemos aquí la duplicación de la Forma, que una vez, como refleja en sí es el Contenido, y otra, como no reflejada en sí, la existencia exterior indiferente al contenido. En sí tenemos aquí la relación absoluta del Contenido y de la forma; esto es, el convertirse del uno en la otra" (76).

Hagamos referencia, para terminar con esta parte, al problema del conocimiento de la realidad esencial visto desde el fenómeno, así como a la estructura de esta realidad esencial de cara al Contenido y a la Forma. Por lo que toca al conocimiento de la realidad esencial desde el punto de vista de la Forma y del Contenido, lo que se tiene es un conocimiento del Ser Fenoménico de esa realidad, que puede acercarse más o menos a la Forma o al Contenido; todo depende de lo conocido en ese ser. Lo que es innegable es que, a nivel de conocimiento, Forma y Contenido marchan unidos, se interpretan y se trastocan mutuamente; es decir, la Forma se vuelve Contenido y el Contenido se vuelve Forma. Desde el punto de vista de la realidad, Contenido y Forma expresan niveles distintos, contrarios, pero intrínsecamente ligados, de esta realidad. Niveles de realidad (accidentales y necesarios) unitariamente articulados y en tránsito recíproco. Contenido y Forma son dos momentos Ontológicos-Lógicos de la estructura del Ser y de su conocimiento por parte del hombre; ambos hacen alusión al Ser Fenoménico.

c) La Relación. Este el tercer momento del Fenómeno. El mismo hace referencia fundamentalmente a la articulación entre Contenido y Forma. De entrada digamos que Hegel distingue tres niveles distintos de vinculación. En primer lugar, está la Relación inmediata del Contenido y la Forma, la relación de identidad y de totalidad entre ambos. Como apunta Hegel: "la relación inmediata es la del todo y las partes: el Contenido es el todo y consta de las partes (de la Forma), de su opuesto... Pero son partes solamente en su relación de identidad entre sí, o en cuanto, tomadas en conjunto, constituye el todo... La relación del todo y las partes es la relación y conservación inmediata... de la identidad consigo en la diversidad. Se pasa de las partes y del todo a las partes, y se olvida que lo uno es antítesis con lo otro"(77). Este momento relacional entre el todo y las partes, entre Contenido y Forma, corresponde al 
ser en sí de la Relación; del "todo idéntico a sí, como ser en sî”, como diría Hegel.

En segundo lugar, este momento inmediato de la Relación posee dinamismos intrínsecamente negativos que fuerzan a la diferenciación de los dos términos. Y ello tanto a nivel de conocimiento como a nivel de la estructura 'física' de lo real. Para el caso, en el conocimiento, "tomada una cosa primeramente como todo, luego se pasa a la determinación de las partes; esta determinación es por consiguiente olvidada, y lo que era parte es considerado como todo; luego se pasa a las determinaciones de las partes, etc., hasta el infinito"(78). Y del lado de la realidad sucede algo similar: ella, por la fuerza de sus contradicciones internas, va desplegando sus determinaciones; determinaciones que se sintetizan y totalizan en determinadas fases del proceso y que luego dan paso a otras determinaciones, etc. Son estas determinaciones las que se desenvuelven ya sea como Forma o ya sea como Contenido, en una unidad en la que los dos términos ya diferenciados se convierten mutuamente.

En tercer lugar, se tiene como último momento de la Relación a su ser para sí. Este estadio se da solamente cuando la parte y el todo, el Contenido y la Forma han alcanzado su articulación más plena y más desarrollada; cuando ya han desarrollado la totalidad de sus posibilidades y estas han sido expresadas en una síntesis dialéctica; es decir, cuando el Contenido y Forma, parte y todo, han sido subsumidos en todo su despliegue en una unidad superior que recoge lo mas real de cada uno de ellos, en una unidad que los supera. La relación de Forma y Contenido, parte y todo, a estas alturas de proceso es de identidad plena. Como apunta Hegel, "su identidad es la identidad plena, el Contenido"(79).

Y como este momento de plenitud unitaria de lo real, este proceso de unificación de sus determinaciones, no puede ser captado si no por el espíritu humano, en y a través de su propio devenir, resulta de ello que ese momento de síntesis unitaria es "uno" con la reflexión intelectual que da cuenta de la misma: justamente, la totalidad plena, la identidad total, es la de la unidad cosa plenamente desarrollada-mostrada (reflejada) por la reflexión humana. Es como escribe Hegel, "la unidad de la reflexión en sí y de la reflexión en otro, que es puesta en el movimiento de la fuerza; ambas son una totalidad misma, y esta unidad hace de ellas un contenido"(80); una totalidad, por tanto, en la cual "lo exterior... es primeramente el mismo contenido de lo interior. Lo que es interno existe también exteriormente y viceversa; el fenómeno no muestra nada que no esté en la esencia, y en la esencia no hay nada que no esté manifestado"(81). La captación de esa totalidad sintética de fenómeno y esencia, de Contenido y Forma, de parte y todo, así como el despliegue ontológico de esa realidad, constituye unitariamente este tercer momento de la relación que estamos examinando: el momento de la Relación Contenido-Forma como algo para sí. 
En resumen, en este segundo apartado de la Doctrina de la esencia encontramos tres Conceptos Fundamentales: Fenómeno, Contenido-Forma y Relación. El concepto de Fenómeno hace referencia a la dimensión mostrativa-exteriorizable de la Esencia; el de Contenido-Forma a dos elementos de la realidad esencial de cara a su expresión fenoménica, esto es, a su expresión como interioridad fenoménica con carácter de Ley (Contenido) y a su expresión concreto-accidental (Forma); y la de Relación a los vínculos procesuales entre Forma y Contenido, entre Esencia y Existencia, que van del En sí, a través de la negatividad hacia el Para sí. Asimismo, son Conceptos que además de manifestar tres momentos estructurales, físicos, del Ser, manifiestan tres caracteres esenciales de su conocimiento.

\section{iii) La Realidad}

a) Lo real. Ante todo, se tiene que decir qué es la Realidad para Hegel. Sin mayores preámbulos citemos lo que dice él mismo al respecto: "la Realidad - escribe- es la unidad de la esencia y la existencia, o de lo interior y lo exterior hecha inmediata. La manifestación de lo real es lo realismo; así que este permanece en aquella igualmente esencial, y solo en tanto es esencial en cuanto está en inmediata existencia exterior"(82). Por tanto, se tiene realidad (en la inteligencia y fuera de ella), en la unidad de lo esencial (lo interno) y lo existencial (lo externo) hecha inmediata; en la unidad captada (si se trata del conocimiento) o manifestada (si se trata del Ser mismo) de esencia y existencia, de modo inmediato y pleno. Como dice Findlay, "por 'real' Hegel entiende lo que está realizado, plenamente actualizado y operativo: lleva consigo, al menos en principio, individualidad, carácter de definido, concreción sensible, ser aquí y ahora, y un contexto completo de condiciones"(83).

En tal sentido, se tiene Realidad sólo en la unidad plenamente actualizada, realizada, de esencia y existencia, de Contenido y Forma, en el aquí y ahora, real y presente, de la plena individualidad; en la presencia plena de lo que debe ser. Y es que como dice Findlay "el que la realidad lleve consigo la inmediata concreción sensible no es, sin embargo, recíproco: no todo lo que es palpable y sentido es elevado por ello a la realidad. Hay muchas cosas inmediatamente presentes que, en el sentido hegeliano, no alcanzan la Realidad, que son 'existencia bajas y no verdaderas', que en modo alguno son realmente lo que tendrían que ser"(84). En resumen, la realidad "es el Todo que ha logrado identidad con sus partes, la fuerza plenamente expresada en sus Manifestaciones, y el Interior que se ha convertido en lo completamente exterior"(85). Pero la Realidad no se expresa con la plenitud a la que estamos aludiendo de una vez y por siempre. Antes pasa por fases más primarias. Esto nos remite al segundo momento del concepto de Realidad.

b) Lo Posible, la posibilidad. Este segundo momento de la realidad toca dos aspectos de la misma: la Realidad actualizada en todas su riqueza y la Reali- 
dad considerada del modo abstracto. En el primer caso, es lo que Hegel llama el aspecto 'modal' de la realidad, "que debe necesariamente pensarse como presente en la realidad, puesto que cuanto es real es posible"(86). En el segundo caso se trata de una Posibilidad abstracta que se corresponde con una realidad igualmente abstracta. "La Forma más elemental de Realidad es la que abstrae - anota Findlay - de un contexto necesitante, que se piensa como inmediata. Y así concebida es meramente una Realidad proforma, o Formal, y la Posibilidad que le corresponde es asimismo una posibilidad abstracta, meramente formal, una posibilidad que es suficientemente establecida por la mera ausencia de contradicción”(87).

Recapitulando lo dicho, la Realidad está estructurada y se estructura de acuerdo a tres niveles metafísicos distintos, pero unitariamente articulados: como simplicidad abstracta, como realidad negativo-dialéctica, y como realidad totalizada y multideterminada. Es decir, como en Realidad en Sí, como Realidad Determinada y como Realidad para Sí. Esa realidad, asimismo, dependiendo del nivel procesual en que se encuentre, da paso a la Posibilidad abstracta o a la Realidad Posible.

Y, finalmente, esos niveles de Realidad y Posibilidad de lo Real, del Ser, son niveles que expresan tanto la estructura y estructuración física del Ser Real como momentos esenciales del proceso de su aprehensión intelectiva. Respecto al conocimiento, captar la Realidad de un modo evanescente, por así decirlo, es estar en una fase de reflexión de carácter elemental, abstracto; es estar, en otras palabras, en una fase de Realidad abstracta en el conocimiento. Por lo que toca a la Realidad, pasa más o menos lo mismo. En sus momentos iniciales, cuando no ha empezado a generar dentro de sí y desde sí sus determinaciones, se encuentra en un estadio de Realidad abstracta. Procesual y dinámicamente va a dar paso a sus subsiguientes momentos, en los que se cualificará y concretará.

c) Lo Contingente y lo Necesario. Primero, la Contingencia. Esta categoría está estrechamente ligada a la Posibilidad ya que ella es un Posible que puede o no realizarse, que puede o no actualizarse. Y que, incluso, como hecho actualizado no tiene una razón interna que lo fuerce a ser de un modo u otro; cosa distinta a lo que sucede con el hecho real necesariamente realizado de una manera determinada y de la posibilidad que dio paso a esa realidad y no a otra. Como escribe Findlay: "hay muchos hechos reales mas o menos superficiales que son también meramente fácticos, para las cuales no puede darse ninguna razón científica o filosófica que sean así y no de otra manera... Es perfectamente obvio que por Contingente entendemos lo que es sin suficiente fundamento, aquello cuyo contrario es igualmente sensible" (88).

En segundo lugar, lo Necesario. Esta categoría completa a la anterior. De algún modo, como opina Findlay, en la Contingencia, realidad y posibilidad, o viceversa, están en una combinación "insatisfactoria" e "inquietante" ya que el 
vínculo (regido y exigido por un Fundamento) entre una posibilidad irrealizable y su no realización fáctica no queda claro. Justo aquí interviene la categoría de Necesidad, de Necesariedad. Lo Necesario expresa el vínculo unívoco entre la Posibilidad realizable y su realización. "Lo Necesario es por una parte Real y en cuanto Real no necesita Fundamento, pero también incluye en sí una Posibilidad, que ha sido hecha Realidad mediante la eliminación de la Posibilidad contraria por algún Fundamento suficiente. La única Posibilidad genuina es la única Posibilidad, una posibilidad que ha sido elevada a Necesidad y que coincide con lo Real" (89). La conversión de esa posibilidad genuina en Realidad es, pues, una conversión Necesaria.

En resumen, las categorías fundamentales de la Esencia son tres: Existencia, Fenómeno y Realidad; que a su vez están subdivididas por alrededor de trece subcategorías básicas. Lo importante de ello es que todas y cada una de las mismas expresan un doble carácter de lo real: su carácter estructural manifestado a través del intelecto. $\mathrm{O}$, dicho de otra manera, las categorías expuestas son expresión, a una, de la índole misma de la Realidad, del Ser, y de las fases por las que se mueve el conocimiento, la Reflexión, en la búsqueda de la ultimidad estructural de aquélla. Asimismo, son categorías cuya trabazón lógica manifiesta las fases puras en las que se ha movido el Absoluto, y que han sido captadas en su máxima concreción en la Historia de la Humanidad, concretamente en la Historia del Espíritu, que no ha sido otra cosa, por lo demás, que un despliegue y captarse a sí mismo del propio Absoluto por medio del hombre y su quehacer histórico-filosófico.

\section{Categorías fundamentales del concepto: concepto subjetivo, objeto e idea}

En la tercera sección de la Lógica, la Doctrina del Concepto, Hegel desarrolla todo un conjunto de categorías que tienen que ver con el Concepto, con el pensamiento superior. Dado que nos extenderíamos demasiado si intentásemos explicar la mayor parte de esas categorías, aunque fuera someramente, lo único que haremos es centrar nuestro trabajo en algunas de ellas. Nos valdremos, para ello, de la obra de Findlay, ya citada, y de algunos textos de Hegel de la Enciclopedia.

Ante todo, veamos cuáles son las categorías (y sub-categorías) que aparecen sobre el Concepto en la obra de Hegel ya mencionada. Las fundamentales son tres: a) el Concepto Subjetivo, b) el Objeto y c) la Idea. Y se subdividen así: el primero -El Concepto Subjetivo- consta de diez submomentos: el Concepto como tal, el Juicio, el Juicio Cualitativo, el de Reflexión, el de Universalidad, el del Concepto, el Silogismo, el Silogismo Cualitativo, el de Reflexión y el de Necesidad; el segundo —el Objeto- consta de tres: el Mecanismo, el Quimismo y la Teleología; el tercero - la Idea - consta de cuatro: la vida, el Conocer, el Querer y la Idea Absoluta. Todos los aspectos mencionados conforman el órga- 
no categorial de la tercera sección de la Ciencia de la Lógica. Detengamos nuestra atención en las tres categorías fundamentales; pero, antes, caracterizamos la índole de la tercera sección.

Antes, en la primera y segunda sección de la Ciencia de la Lógica, Hegel se había ocupado de las categorías del pensamiento, pero en relación a objetos materiales; es decir, que estaban "todas objetivamente orientadas: era función suya captar y organizar cosas y materiales que como tales no eran pensamientos, ni 'puestos' como esencialmente referidos a pensamientos, en ningún sentido"(90). Cosa distinta a lo sucedido con las categorías a las que prestamos atención ahora. Las mismas, son nociones, conceptos, que se refieren al propio pensamiento. "Las nociones con las que vamos a tratar -aclara Findlay-, estarán orientadas subjetivamente, tanto como objetivamente; serán nociones de nociones que refieren explícitamente aquello de que tratan a la vida central y coordinadora del pensamiento. Puede decirse que hasta aquí hemos venido empleando nociones, pero no pensándolas como nociones"(91). En otras palabras, en la Doctrina del Concepto, de la Noción, se reflexionará sobre las categorías en las que se estructura el propio pensamiento; que tratan de la vida central y coordinadora de éste; en fin, la estructura categorial 'conceptual' en la que se fundamentan los conceptos de lo real: serán, por tanto, nociones de nociones. Pero, ¿qué es el Concepto? Para Hegel, el Concepto es el nivel más elevado de conocimiento de lo Real por parte del Hombre.

Dicho de otra manera, el Concepto es la expresión teórica más profunda de la Lógica interna de la Realidad natural-histórica, y, en el fondo, de la Lógica en que se mueve el Absoluto y en la cual éste se reconoce. Por ello es que se tiene que tratar el Concepto en cuanto tal: su movimiento manifiesta el movimiento de la realidad y del Absoluto, el conocimiento de lo real por parte del hombre y el conocimiento de sí del Absoluto. Por tanto, el Concepto además de expresar la conciencia teórica más elevada de la realidad, realiza un movimiento real como concepto. Es a este movimiento del Concepto al que se refiere Hegel en esta tercera sección de lógica. Y al Concepto así entendido lo define como "lo que es libre... puesto que cada uno de los momentos es todo el Concepto, y puesto con él en unidad inseparada. El Concepto es, pues, lo que en su identidad consigo es en sí y por sí determinado"(92). Dicho con otras palabras: "el Concepto es un saber verdadero, no el pensamiento como puro universal; además el Concepto es el pensamiento, el pensamiento en su vitalidad y actividad... el concepto es lo determinado de sí, lo que se particulariza a sí mismo"(93). La tarea de Hegel es, en este sentido, describir los momentos del devenir de ese pensamiento-concepto, verdadero y vital.

Esa actividad y vitalidad es, por otro lado, de carácter procesual. Es decir, que el Concepto no da cuenta de la verdad del Ser de modo inmediato, sino gradualmente. Recordemos que lo inmediato es lo más simple —Ontológica y 
Lógicamente- y que el Concepto —en orden al conocimiento- de lo que más carece es de simplicidad. Pero bien, esto no nos interesa aquí. Decíamos que el Concepto no se da de modo inmediato. Y ello si nos referimos al proceso global del conocimiento humano (que se inicia incipientemente en el misticismo y la religión) o si nos referimos al propio conocimiento conceptual. En este caso, el nivel conceptual pleno solo se logra al final de todo un recorrido Lógico-cognitivo. Este recorrido, que es el desarrollo procesual del concepto, Hegel lo enuncia así: "el proceso del concepto ni es ya el pasar ni el reflejarse en otro, sino que es el desarrollo (...), porque las diferencias son puestas inmediatamente como idénticas entre sí y con el todo, y la determinación es puesta como un libre ser de todo el concepto"(94).

De lo que se trata es de estudiar este movimiento conceptual como determinante del Ser, como su unificador, en el cual éste es revelado de una forma más racional y especulativa. En la Noción, en el Concepto, cabalmente realizado se da la unidad de lo Universal, lo Específico y lo Individual. "Tener una Noción - por tanto- es pensar las cosas universalmente, ordenarlas bajo caracteres comunes en los que sumerjan las diferencias específicas y la cruzada inmediatez individual de esas cosas"(95).

\section{i) El Concepto Subjetivo}

Este primer momento del Concepto nos remite, al nivel del pensamiento, al primer momento del Ser, es decir, a la Identidad. Es el nivel abstracto, primario, elemental, desde donde inicia su marcha el Concepto; por lo cual, asimismo, contiene dentro de sí indiferenciadamente, la totalidad de momentos y aspectos esenciales del Concepto. Hegel lo apunta claramente al decir: "el Concepto Subjetivo es aún formal; pero no ya que deba tener o recibir otro contenido diverso de sí mismo. Como la forma absoluta misma, el concepto es toda determinación; pero como ésta es en su verdad. Y por esto, aunque abstracto, es propiamente lo que es concreto, lo que es concreto sin más el sujeto como tal"(96). Porque, si cuando se trataba del Puro ser o de las determinaciones puras de la reflexión —que es en general su estadio metafísico de En sí-, ya en ellas se encontraban la totalidad de determinaciones potenciales del Ser o de la Reflexión, no cabe duda de que a nivel del pensamiento conceptual, ya en concepto subjetivo-que es el En sí del concepto- se encuentran no sólo la totalidad de momentos y determinaciones del mismo concepto, sino la totalidad de momentos y determinaciones del Ser y de la Reflexión, que son determinaciones de aquél. Es el Ser en sí del Concepto, como la universalidad total e indiferenciada del ser y de la reflexión, "es lo que es idéntico consigo mismo, con la expresa significación de que en lo universal está contenido lo particular y lo individual... Lo absolutamente concreto es el espíritu, el concepto en cuanto existe como concepto, distinguiéndose en su objetividad... Todo otro concreto, por rico que sea, no es tan íntimamente idéntico a sí mismo, y, por tanto, no es en sí mismo tan concreto"(97). 
El Concepto Subjetivo es, pues, el estadio del En sí del concepto; el estadio abstracto del mismo, en el que se encuentran indiferenciadas la totalidad de determinaciones del Concepto y de la realidad entera. Lo cual no quiere decir que para Hegel el Concepto cree o produzca la Realidad o el Ser. Más bien, la determinación hegeliana del concepto respecto de la totalidad real está pensada en términos kantianos. En este sentido, está pensada, más que como producción de cosas, como apropiación unificadora y universalizante de lo dado sensiblemente. Es decir, como anota Hegel, "la captación intelectual de un objeto no consiste en otra cosa que en que el yo hace propio ese objeto, lo penetra y lo atrae a su propia forma, es decir, la forma de una universalidad que es inmediatamente determinación, y una determinación que es inmediatamente universalidad... A través de la captación conceptual, el ser-en-y-para-sí que el objeto goza en la vista directa o en el pensamiento es transformado en un ser meramente puesto: el Yo penetra el objeto pensantemente. Pero al estar el objeto en el pensamiento es por primera vez en y para sí"(98).

Aquí tocamos otra vez la idea hegeliana de la unidad total que hay entre el pensamiento y la realidad. Definitivamente, para Hegel el Ser sólo alcanza la totalidad de su desarrollo cuando existe un pensamiento que expone esa totalidad; la totalidad real es sólo Totalidad por la unidad de Ser y Pensamiento, de la Realidad pensada o de la Realidad que se piensa. Y si ello es así, como se desprende de lo dicho, la Realidad por antonomasia es la realidad histórica; solamente en ella se da la total unidad entre pensamiento y ser, entre teoría y práctica.

En resumen, el Concepto Subjetivo nos remite a un estadio inicial del desarrollo del concepto. Es, asimismo, la categoría básica para conocer y dar cuenta conceptualmente del mismo Concepto. En segundo lugar, como estadio inicial del Concepto encierra dentro de sí la totalidad de posibilidades de determinación de lo real entero, que no se constituye como real plenamente sino por el pensamiento conceptual. Lo que no quiere decir que sea el pensamiento el que produzca lo real; es sólo un momento esencial de éste. Finalmente, la realidad histórica se nos muestra como la máxima realidad, ya que ella sintetiza todas las posibilidades del Ser en pleno desarrollo.

\section{ii) El Objeto}

Una vez que hemos viste los submomentos del Concepto Subjetivo --esto es, el juicio y sus derivaciones-, centrémonos en la objetividad, teniendo en mente que el Concepto debe determinarse negativamente. Pues bien; en este orden de ideas, la Objetividad, como momento esencial del Concepto, no se opone a la Subjetividad, sino que hace referencia al carácter que deben cobrar los objetos pensados en el pensamiento como hecho necesario en su diferenciación y manifestación de sus determinaciones. Como anota Findlay, la Objetivi- 
dad "representa más bien lo que el pensamiento debe pensar si ha de ser fiel a su sí-mismo universalizador, si ha de ver las realidades individuales ante él como individualizando y especificando Universales"(99).

En este sentido, el Concepto Subjetivo sale de su determinación, de su inmediatez abstracta, Objetivándose en momentos conceptivos individuales, separados unos de otros, en los que la separación se vuelve una mediación, una negación de la inmediatez. En palabras de Hegel: "indiferente respecto de su unidad inmediata; es un romperse en seres distintos, cada uno de los cuales es el mismo, la totalidad. El objeto es, por tanto, la absoluta contradicción de la independencia completa de lo múltiple, y, además, de la dependencia completa de la misma, la dependencia de la independencia"(100). E, incluso, esto aparece más claro aún en un texto de la Ciencia de la Lógica citado por Findlay. En el mismo dice Hegel: "en el presente punto de vista de nuestro tratamiento la Objetividad tiene un primer lugar en el significado del Carácter de en-y-para-sí-misma de la Noción, la Noción que ha transformado la mediación puesta en su determinación a una relación inmediata en sí misma. Esa inmediatez es consecuentemente ella misma inmediata y completamente empapada en la Noción, así como su totalidad es inmediatamente idéntica con su ser"(101). Lo último de la cita ya fue de alguna manera insinuado por nosotros páginas atrás. Lo que ahora nos interesa es su primera parte. En ella lo que Hegel quiere decir es que la Noción transforma, en virtud de sus potencialidades internas, las relaciones inmediatas de sí misma (sus relaciones difusas como concepto Subjetivo) en relaciones mediatas, puestas como determinación. Este autodeterminarse del Concepto, este mediatizarse, es justo su Objetivación; si se prefiere su momento de determinación. Igualmente, representa el momento negativo del Concepto, el momento por el cual y en cual éste niega su totalidad inicial y se particulariza en una variedad de partes, de aspectos, de determinaciones, desconectadas entre sí y absolutizadas. Hegel ejemplifica este proceso de Objetivación haciendo referencia a la mónada de Leibniz. "En la mónada —escribe — nada viene del exterior...También esta simple totalidad se rompe en la absoluta multiplicidad de las diferencias, de modo que éstas son mónadas independientes... La filosofía de Leibniz es, por consiguiente, la contradicción completamente desarrollada" (102).

Porque, en definitiva, la Objetivación no es más que el Concepto Contradictoriamente desarrollado; su momento negativo; el momento por el cual el Concepto despliega sus determinaciones internas dándoles un rango propio e independiente de la totalidad. Y esto compete, al igual que el momento del Concepto Subjetivo, al Concepto en cuanto tal; al desarrollo que sigue el Concepto en el conocimiento verdadero de las cosas y de sí mismo. En este sentido, pues, el conocimiento conceptivo va dando cuenta de las cosas - de las determinaciones de ellas — y de sí mismo — de sus determinaciones- en y por la Objetividad. Más aún, si pensamos en la determinabilidad misma de las cosas es a la categoría de Objetivación a la que tenemos que prestar atención. Y desde aquí lo que 
se tiene que afirmar es que las cosas se determinan (se diversifican) en y por este momento conceptivo de Objetivación.

No que el concepto objetivo produzca las determinaciones de la realidad, en tanto que realidad, sino que es un momento esencial en su despliegue como determinaciones. Sin él, las determinaciones de lo real no serían plenas determinaciones; o, peor aún, lo real carecería de ellas. Sería realidad, pero no plena realidad, sería una realidad difusa, incompleta, no plenamente desarrollada. Porque lo que está de fondo en la perspectiva Hegeliana es la idea de la unidad realidad-pensamiento como totalidad plena y realmente real. Un momento esencial del desarrollo de esta totalidad es el despliegue negativo de sus determinaciones y ello solamente se puede lograr, sólo es posible, por el pensamiento que integra esa totalidad, es decir, por el pensar conceptivo. La Objetivación, por tanto, a la vez que momento o fase por lo que atraviesa el concepto en su conocimiento de sí mismo y de lo real, es el momento por el cual la unidad pensamiento-realidad, naturaleza-historia, se autodetermina y autodiversifica procesualmente.

Finalmente, dejemos aparte el carácter propio de este proceso de desarrollo por el que atraviesa la unidad pensamiento-realidad en lo que toca a su momento de Objetividad; es decir, en lo que respecta al carácter de sus fases de mecanicidad de Quimicidad, y teologicidad. Sólo retengamos que son fases o momentos de la determinación conceptiva. Pasemos al último momento, a la última categoría de la Doctrina del Concepto.

\section{iii) La Idea}

Esta última fase de la Lógica es, para Hegel, la síntesis plena entre el Concepto Subjetivo y Objetivo. Desde el punto de vista del desarrollo del Concepto, la Idea expresa la totalidad más plena y autoposesión de las múltiples determinaciones del Concepto; la unidad equilibrada de sus momentos anteriores que han sido subsumidos y superados. Como bien lo anota Findlay, "la Idea, la etapa final de la lógica, encarna para Hegel una perfecta unidad y equilibro entre la 'Subjetividad', estudiada en la Universalidad, especificidad e Individualidad de la pura noción, y la Objetividad tratada bajo los tres epígrafes de Mecanismo, Quimismo y Teleología"(103). O como Hegel mismo lo apunta en la Enciclopedia, "la idea es lo verdadero en sí y para sí, la unidad absoluta del Concepto y de la Objetividad. Su contenido ideal (en tanto que puro concepto) no es otra cosa que el concepto en las determinaciones del concepto: Su contenido real es sólo la expresión que el concepto se da de sí mismo en la forma de existencia exterior; y esta forma, incluida en la identidad del mismo, en su poder; por tal modo, se mantiene en sí mismo"(104). Es decir, que vista la Idea (analíticamente) como movimiento del Concepto lo que en ella se tiene es al propio Concepto en la Multiplicidad de sus determinaciones unitariamente articuladas; si se ve a 
la idea, por otro lado, de cara a la realidad lo que se tiene es la manifestación exterior totalmente desarrollada de la unidad Ser-Pensamiento. En este sentido, la Idea sintetiza, por un lado, la totalidad de determinaciones del Concepto tomado en sí mismo; por otro lado, expresa el conocimiento más profundo y elevado que el Concepto pueda lograr de sí mismo y de la Totalidad plenamente desarrollada de las cosas reales, Y, más aún, es el momento último y posibilitante para que éstas alcancen el estatuto de Totalidad plena; de unidad diversificada y concretizada totalmente en función de sus momentos naturales-históricos. Sólo aquí se puede hablar de plena realidad: el Concepto (que es el nivel más alto de conocimiento) se ha explayado totalmente y reconoce sus momentos fundamentales; la Realidad ha alcanzado su dimensión plena de Realidad porque ha desplegado la totalidad de sus potencialidades histórico-naturales y las ha sintetizado unitariamente; y el Hombre al conocer el devenir y planificación del Concepto y la Realidad, así como su mutua fundamentación y estructuración, se conoce a sí mismo y, en su virtud, desarrolla sus potencialidades y las totaliza.

Esto es para Hegel, en resumidas cuentas, la verdadera Totalidad Real: Conocimiento que se conoce a sí mismo (para sí del Concepto); Naturaleza que se ha historizado y que ha desarrollado y subsumido la totalidad de determinaciones espirituales-materiales (para sí de lo Real); y Hombre que ha desarrollado y superado sus múltiples determinaciones conociendo el devenir del Concepto y su síntesis, conociendo la Totalidad de determinaciones de lo Real, y conociéndose, en consecuencia, a sí mismo (para sí del Hombre). Todo lo cual es una sola y misma Realidad, no pudiendo alcanzar un aspecto de la misma su estatuto más pleno, sino por el desarrollo pleno de los otros. Así, por ejemplo, el Concepto no puede alcanzar el nivel de Idea (con todo lo que ello conlleva) si no es porque la Realidad, el Ser, se ha explayado históricamente y ha sido conocido por el intelecto humano; y así con todo lo demás. Esto que afirmamos aparece con claridad en un texto de Kojeve en La Dialéctica de lo Real. En él se puede leer: "todo-lo-que-es-Verdad, la entidad verdadera, lo Verdadero, das Wahre, es una entidad real, o el propio ser, en tanto que revelado correcto y completamente por el discurso coherente con un sentido (Logos). Y esto es lo que también llama Hegel Begriff, concepto; término que significa para él (...) no 'concepto abstracto', separado de la unidad real con la cual se relaciona, sino 'realidad comprendida conceptualmente'. Lo Verdadero y el Concepto son, como dice el propio Hegel, un Logisch-Reellea, algo lógico y real al mismo tiempo, un concepto realizado a una realidad concebida"(105). Y esta plena realidad se subsume totalmente en la Idea; ella, como expresión de la Verdad de la Realidad, presupone no sólo el desarrollo natural-histórico de la misma, sino también el desarrollo y auto-poseción del hombre.

Entonces, pues, la Idea señala la culminación de todos los procesos de desarrollo y su manifestación plena: a nivel de conocimiento, es la captación total de la Verdad de lo Real y del propio conocimiento; a nivel real-histórico, expresa 
el desarrollo último de la totalidad Ser-Pensamiento, de la realidad por excelencia; y a nivel del hombre, manifiesta el saber más profundo que éste puede lograr de sí mismo y de la realidad. En suma, señala la máxima realización del "ser revelado por el discurso" (la verdadera y plena realidad), del "discurso revelador de la realidad" (el Concepto) y del ser que mediante ese discurso "conoce lo real y se conoce a sí mismo" (el hombre). Porque, en definitiva, la Idea, a la vez que es síntesis superada del Concepto Subjetivo, es expresión de la Verdad de lo Real; Verdad que no puede ser captada si no por un momento esencial de esta realidad (el pensamiento) en el momento final (o al menos, mas elevado) de su desarrollo como realidad natural-histórica, y por un ser -el hombre-, que, siendo parte de la realidad, ha alcanzado un desarrollo tal de sí que está en condición de penetrar teóricamente en su estructura lógica.

Para finalizar, dejemos constatado que la categoría de Idea no se agota en lo esbozado por nosotros, ni mucho menos. Ella misma, para llegar a expresar totalmente su propia índole y la de la realidad, se desarrolla procesualmente en cuatro fases fundamentales: la Idea en su Inmediatez, la Idea como Conocimiento, la Idea como Actividad Práctica, y la Idea Absoluta"(106). Pero para los efectos de la presentación de la Lógica de Hegel basta con lo dicho.

\section{Conclusión}

Como conclusión general, hemos de decir que presentada a grosso modo la estructura de la Lógica hegeliana se ve con bastante claridad la perspectiva dialéctica que la sustenta. En primer lugar, esto se corrobora observando la articulación triádica de la misma vista en su conjunto. Sus tres secciones básicas -el ser, la esencia y el concepto- expresan los momentos diversos en que se desarrolla la totalidad de lo real; momentos que procesualmente van articulándose (en virtud de la negatividad que introduce el trabajo) hacia la conceptualización. Igualmente, en segundo lugar, se observa la misma estructura triádica al examinar los componentes de cada uno de los planos de lo real tocados por el conjunto de la Lógica.

Así, en el plano del Ser (cualidad, cantidad, y medida), de la Esencia (existencia, fenómeno y realidad) y del Concepto (concepto objetivo, objeto e idea), se encuentran caracterizaciones dialécticas de cada uno de los planos. E incluso en algunos sub-momentos, como es el caso de la Idea, se encuentra el mismo proceder dialéctico y triádico. Y ello no es para menos. Para Hegel, la totalidad del proceso de desarrollo de lo real se entiende como un movimiento del En sí (lo indeterminado), pasando por la determinación del Ser determinado (la negatividad), hasta el Para sí (la reconciliación de las determinaciones). Consecuente con su perspectiva de totalidad, de negatividad y de procesualidad, Hegel se aproxima a los distintos procesos y da cuenta de ellos triádicamente. Tanto es así que la negatividad no le serviría para explicar los procesos reales si su 
realidad fuese paralizada o mecánica; es decir, si aislara los hechos o desde unos hechos aislados pretendiera explicar el todo. La Negatividad le sirve para explicar lo real total o parcialmente porque está pensando el ámbito de lo real en términos de Naturaleza e Historia; es decir, como totalidad articulada por el trabajo humano; asimismo, evita todo mecanismo porque la perspectiva totalizadora en la que se mueve, en virtud de la novedad que implica la dialéctica del trabajo, es siempre abierta. De Hegel acá las ideas de totalidad, de proceso y de la dialecticidad intrínseca al trabajo del hombre - por el cual se unifica la historia en sí misma y con la naturaleza dando lugar a la verdadera totalidad-, han alcanzado mayor precisión analítica y conceptual; pero es él a quien corresponde el no poco mérito de haberlas legado a la filosofía occidental para siempre y de haber dado, desde ellas, el estatus de máxima realidad a la historia. Este es el grandioso mérito de Hegel.

\section{Notas}

1. Hegel, G.W., Introducción a la Historia de la Filosofia. Madrid, Aguilar, 1975

2. Kojeve, A., La dialéctica de lo real y de la idea de la muerte en Hegel. Buenos Aires, La Pléyade, 1972

3. Ibíd.

4. Ibíd.

5. Hegel, G.W., Enciclopedia de las ciencias filosóficas. México, Porrúa, 1973

6. Kojeve, A., La dialéctica....

7. Hegel, Enciclopedia...

8. Kojeve, A., La dialéctica... pp. 15-16

9. Ibid. p. 16

10. Ibíd. p. 18-19

11. Ibid.

12. Ibid., p. 32

13. Ibid., p. 33.

14. Ibíd., p. 29

15. Hegel, Introducción a la ... p. 259

16. Ibid., p. 255

17. Ibid., p. 256

18. Ibid., p. 256-257

19. Ibid., p. 298

20. Ibíd., p. 299

21. Hegel, Introducción a la... "Prólogo" de Eloy Terrón, p. 14

22. Kojeve, A., La dialéctica de..., p. 7

23. Hegel, Enciclopedia..., p. 54

24. Hegel, Introducción a la..., p. 52

25. Hegel, Enciclopedia..., p. 51-52

26. Kojeve, La dialéctica de lo real..., p. 26

27. Ibid., p. 27

28. Hegel, Introducción a la..., p. 53-54

29. Ibíd., p. 54 
30. Kojeve, La dialéctica de lo real... p. 33

31. Hegel, Enciclopedia... p. 52

32. Ibid.

33. Hegel, Introducción a la... p. 59

34. Ibid., p. 59

35. Hegel, Enciclopedia... p. 56

36. Hegel, Introducción... p. 57-58

37. Hirschberger, J., Historia de la filosofia. Barcelona, Herder, 1982, p. 263, T. II

38. Hegel, Enciclopedia... p. 60

39. Ibíd., p. 62

40. Ibid.

41. Ibid.

42. Ibíd.

43. Ibíd., p. 63

44. Ibíd., p. 64

45. Ibíd., p. 44

46. Ibíd., p. 65

47. Ibíd.

48. Ibíd., p. 53

49. Findlay, J. N., Reexamen de Hegel. Barcelona, Grijalbo, 1968, p. 186

50. Ibíd.

51. Hegel, Enciclopedia... p. 66

52. Ibid.

53. La división de la primera parte y de la tercera han sido tomadas de Findlay, J. N., Reexamen de Hegel, ya citado, pp. 191-212; la tercera de la Enciclopedia de Hegel, ya citada.

54. Findlay, J. N. Reexamen... p. 191

55. Hegel, Enciclopedia... p. 68

56. Findlay, J. N., Reexamen... p. 192

57. Ibíd.

58. Hegel, Enciclopedia... p. 69

59. Ibid., p. 70

60. Ibíd.

61. Findlay, J. N., Reexamen de... p. 193

62. Ibíd.

63. Ibid.

64. Ibid.

65. Ibid., p. 194

66. Ibíd.

67. Ibíd., p. 195

68. Ibid.

69. Ibid.

70. Ver Kojeve, A., La dialectica de..., primera parte.

71. Hegel, Enciclopedia... p. 75

72. Ibid.

73. Findlay, J. N., Reexamen..., p. 204

74. Hegel, Enciclopedia..., p. 75 
75. Ibid.

76. Ibíd.

77. Ibid., p. 76-77

78. Ibid.

79. Ibid., p. 77

80. Ibíd.

81. Ibid., pp. 77-79

82. Ibid., p. 79

83. Findlay, J. N., Reexamen..., p. 212

84. Ibid.

85. Ibid., p. 214

86. Ibid., p. 215

87. Ibíd.

88. Ibíd.

89. Ibid., p. 225

90. Ibíd.

91. Hegel, Enciclopedia..., p. 86

92. Hegel, Introducción a la..., p. 48

93. Hegel, Enciclopedia..., p. 86

94. Findlay, J.N., Reexamen..., p. 229

95. Hegel, Enciclopedia..., p. 88

96. Ibíd.

97. Findlay, J. N. Reexamen..., p. 228

98. Ibíd. p. 249

99. Hegel, Enciclopedia..., p. 101

100. Findlay, J. N., Reexamen..., p. 249

101. Hegel, G.W, Enciclopedia..., p. 101

102. Findlay, J. N., Reexamen..., p. 258

103. Hegel, Enciclopedia..., p. 107

104. Kojeve, A., La dialéctica de..., p. 9

105. Findlay, J. N., Reexamen..., pp. 258-259. 